ARTICLE

\title{
Dopants fixation of Ruthenium for boosting acidic oxygen evolution stability and activity
}

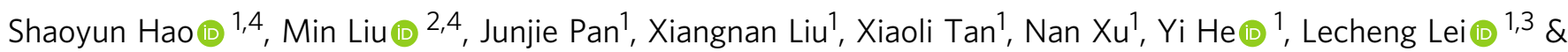
Xingwang Zhang (1,3凶

Designing highly durable and active electrocatalysts applied in polymer electrolyte membrane (PEM) electrolyzer for the oxygen evolution reaction remains a grand challenge due to the high dissolution of catalysts in acidic electrolyte. Hindering formation of oxygen vacancies by tuning the electronic structure of catalysts to improve the durability and activity in acidic electrolyte was theoretically effective but rarely reported. Herein we demonstrated rationally tuning electronic structure of $\mathrm{RuO}_{2}$ with introducing $\mathrm{W}$ and $\mathrm{Er}$, which significantly increased oxygen vacancy formation energy. The representative $\mathrm{W}_{0.2} \mathrm{Er}_{0.1} \mathrm{Ru}_{0.7} \mathrm{O}_{2-\delta}$ required a superlow overpotential of $168 \mathrm{mV}\left(10 \mathrm{~mA} \mathrm{~cm}{ }^{-2}\right)$ accompanied with a record stability of $500 \mathrm{~h}$ in acidic electrolyte. More remarkably, it could operate steadily for $120 \mathrm{~h}\left(100 \mathrm{~mA} \mathrm{~cm}{ }^{-2}\right)$ in PEM device. Density functional theory calculations revealed co-doping of $\mathrm{W}$ and Er tuned electronic structure of $\mathrm{RuO}_{2}$ by charge redistribution, which significantly prohibited formation of soluble $\mathrm{Ru}^{\mathrm{x}>4}$ and lowered adsorption energies for oxygen intermediates.

\footnotetext{
${ }^{1}$ Key Laboratory of Biomass Chemical Engineering of Ministry of Education, College of Chemical and Biological Engineering, Zhejiang University, 310027 Hangzhou, Zhejiang Province, China. ${ }^{2}$ School of Physics and Electronics, Central South University, 410083 Changsha, Hunan, China. ${ }^{3}$ Institute of Zhejiang University-Quzhou, 78 Jiuhua Boulevard North, 324000 Quzhou, China. ${ }^{4}$ These authors contributed equally: Shaoyun Hao, Min Liu. ${ }^{凶}$ email: xwzhang@zju.edu.cn
} 
E lectrochemical splitting water into $\mathrm{H}_{2}$ is considered as a promising technology for storing renewable and sustainable energy $^{1-7}$. Acidic proton exchange membrane (PEM) water electrolyzers is highly desirable because the reaction rate in acidic electrolyte is three or more orders of magnitudes speedier than $\mathrm{pH}$-neutral and alkaline electrolyzers owing to its higher voltage efficiency, more compact designing system, lower ohmic loss, and wider partial load range ${ }^{8-11}$. For decades, anode catalyst for PEM is mainly concentrated on $\mathrm{IrO}_{2}$ with the compromise between stability and activity in acidic electrolyte ${ }^{12-17}$. However, the low mass activity and the high cost extremely hindered its practical applications at large scale. Compared with $\mathrm{IrO}_{2}$, Ru-based materials usually exhibit the relatively higher activity owing to the suitable binding ability of oxygenated intermediate species $\left({ }^{*} \mathrm{OH},{ }^{*} \mathrm{O}\right.$, and $\left.{ }^{*} \mathrm{OOH}\right)$ with the surface active sites ${ }^{18-22}$, but with a poor stability. Recently, a series of Ru-based oxides, including oxide perovskites ${ }^{23,24}, 3 d$ metals doped $\mathrm{RuO}_{2}{ }^{25}$, heterostructured $\mathrm{Ru} @ \mathrm{IrO}_{x}^{3}$ and $\mathrm{Ru}_{1}-\mathrm{Pt}_{3} \mathrm{Cu}^{18}$ with compressive strain, were explored to simultaneously enhance their activities and stabilities in acidic electrolyte by regulating the compositions and surface strain. Although the activities of Ru-based catalysts are attractive, the stability is still only dozens of hours in acidic electrolyte. It has been proven that the over-oxidation of $\mathrm{Ru}$-based materials results in soluble $\mathrm{Ru}^{x>4}$ (e.g. $\mathrm{RuO}_{4}$ ) derivatives ${ }^{14,26,27}$, which seriously hinders the application of $\mathrm{RuO}_{2}$ in the commercial PEM devices.

The over-oxidation of Ru-based catalysts in acidic electrolyte is mainly caused by the oxidation of lattice oxygen, resulting in oxygen vacancies $\left(\mathrm{V}_{\mathrm{O}}\right)$ during $\mathrm{OER}^{9,18,28}$. The generation of $\mathrm{V}_{\mathrm{O}}$ would expose $\mathrm{Ru}$ atoms on the surface $\mathrm{e}^{3,29-32}$, which will be overoxidized to soluble high valence $\mathrm{Ru}^{x>4}$ (e.g. $\mathrm{RuO}_{4}$ ) materials. The over-oxidation of $\mathrm{Ru}$ unavoidably leads to the collapse of the crystal structure, damaging the stability ${ }^{28,29}$. Therefore, it is reasonable to speculate that the over-oxidation of Ru-based catalysts could be thermodynamically hindered during OER if we can tune the electronic structure of $\mathrm{RuO}_{2}$ to make the formation energy of $\mathrm{V}_{\mathrm{O}}$ much higher than the redox $\mathrm{H}_{2} \mathrm{O} / \mathrm{O}_{2}$ energy. Foreign elements doping is the classical and effective strategy to enlarge the localized gap between $\mathrm{O} 2 p$ band centers and Fermi level ${ }^{28,33,34}$. This would enhance the energy barrier for oxidation of lattice oxygen, prohibiting the formation of $\mathrm{V}_{\mathrm{O}}$.

Herein, $\mathrm{W}$ and Er are co-doped into the lattice of $\mathrm{RuO}_{2}$ to modify its electronic structure, avoiding over-oxidation of $\mathrm{Ru}$. By down-shifting $\mathrm{O} 2 p$-band centers, the energy $(\Delta G)$ for the $\mathrm{V}_{\mathrm{O}}$ formation in $\mathrm{W}_{m} \mathrm{Er}_{n} \mathrm{Ru}_{1-m-n} \mathrm{O}_{2-\delta}$ is significantly increased, preventing the generation of soluble high valence $\mathrm{Ru}^{x>4}$. As a result, the representative $\mathrm{W}_{0.2} \mathrm{Er}_{0.1} \mathrm{Ru}_{0.7} \mathrm{O}_{2-\delta}$ offers a record low overpotential of $168 \mathrm{mV}$ to achieve $10 \mathrm{~mA} \mathrm{~cm}^{-2}$ accompanied with a stability at least $500 \mathrm{~h}$ in $0.5 \mathrm{M} \mathrm{H}_{2} \mathrm{SO}_{4}$ electrolyte. It can also be applied as anode catalyst in acidic PEM with a high current of $100 \mathrm{~mA} \mathrm{~cm}^{-2}$ for over $120 \mathrm{~h}$. Thus, tuning the electronic structure of $\mathrm{RuO}_{2}$ to prevent the over-oxidation and dissolution of $\mathrm{Ru}$ opens a feasible route to keep $\mathrm{Ru}^{4+}$ active sites for acidic OER. This work provides the insight to understand the stability of metal oxide catalysts in acidic electrolyte and a strategy to promote their activity and stability by fixing the catalysts.

\section{Results and discussion}

Mechanisms of $\mathrm{W}_{0.2} \mathrm{Er}_{0.1} \mathrm{Ru}_{0.7} \mathrm{O}_{2-\delta}$ toward acidic OER. As for the metal dissolution in acidic electrolyte, it is mainly correlated with the adsorbate evolution and lattice oxygen oxidation mechanisms ${ }^{9,18,35}$. For lattice oxygen oxidation, there are four electrochemical steps as well as a non-electrochemical step for desorption of $\mathrm{O}_{2}$. In lattice oxygen oxidation route, the origin for releasing oxygen was occurred in step III $\left(\mathrm{O}^{*}+\mathrm{H}_{2} \mathrm{O}+\mathrm{O}_{\mathrm{L}}+\right.$
$2\left(\mathrm{H}^{+}+\mathrm{e}^{-}\right) \rightarrow \mathrm{O}_{\mathrm{V}}+\mathrm{O}_{2}+\mathrm{H}_{2} \mathrm{O}+2\left(\mathrm{H}^{+}+\mathrm{e}^{-}\right)$, L represents lattice). With releasing oxygen from the lattice of electrocatalysts, the oxygen vacancies were created, in turn beneficially enhancing the OER activity (Fig. 1a, c) ${ }^{28}$. However, in acidic electrolyte, the existing oxygen vacancies would accelerate the over-oxidation of the exposed $\mathrm{Ru}$, leading to the highly soluble $\mathrm{Ru}^{x>4}$ (e.g. $\mathrm{RuO}_{4}$ ) derivatives. Therefore, the structure of $\mathrm{Ru}$-based materials on anodic side would be destroyed with releasing lattice oxygen from catalysts. As compared with lattice oxygen oxidation, there are only four electrochemical steps in the adsorbate evolution way toward OER (Fig. 1b) ${ }^{9,36}$. Simultaneously, in the adsorbate evolution route, $\mathrm{O}-\mathrm{O}$ coupling from $\mathrm{H}_{2} \mathrm{O}$ in steps $\mathrm{I}$ and III was the origin for releasing $\mathrm{O}_{2}$ (step I: $\mathrm{W}_{0.2} \mathrm{Er}_{0.1} \mathrm{Ru}_{0.7}$ $\mathrm{O}_{2-\delta}+\mathrm{H}_{2} \mathrm{O} \rightarrow \mathrm{W}_{0.2} \mathrm{Er}_{0.1} \mathrm{Ru}_{0.7} \mathrm{O}_{2-\delta}-\mathrm{OH}^{*}+\mathrm{H}^{+}+\mathrm{e}^{-}$, step III: $\mathrm{W}_{0.2} \mathrm{Er}_{0.1} \mathrm{Ru}_{0.7} \mathrm{O}_{2-\delta^{-}}-\mathrm{O}^{*}+\mathrm{H}_{2} \mathrm{O} \rightarrow \mathrm{W}_{0.2} \mathrm{Er}_{0.1} \mathrm{Ru}_{0.7} \mathrm{O}_{2-\delta^{-}}-\mathrm{OOH}^{*}+$ $\mathrm{H}^{+}+\mathrm{e}^{-}$) (Fig. 1d). The structures of catalysts would not be destroyed without releasing lattice oxygen. Therefore, effectively enhancing the energy for formation of oxygen vacancies and inhibiting the direct $\mathrm{O}-\mathrm{O}$ coupling together from the lattice of $\mathrm{W}_{0.2} \mathrm{Er}_{0.1} \mathrm{Ru}_{0.7} \mathrm{O}_{2-\delta}$ would be beneficial for maintaining the stability of Ru-based materials in acidic electrolyte (Fig. 1b, d).

Density functional theory (DFT) calculations. In light of the reacted ways toward acidic OER, we carried out DFT studies aiming at rationally tuning the electronic of $\mathrm{RuO}_{2}$. To enhance the acidic OER stability, the energy for $\mathrm{V}_{\mathrm{O}}$ formation should be thermodynamically suppressed. Density of states (DOS) from DFT was established to investigate how W and Er synergistically rationalize the $\mathrm{Ru} 4 d$ and $\mathrm{O} 2 p$ orbitals in $\mathrm{RuO}_{2}$ (Fig. $2 \mathrm{a}$ and Supplementary Fig. 1). The DOS spectra shows that O $2 p$ band center $\left(\varepsilon_{\mathrm{p}}\right)$ moves from $-3.31 \mathrm{eV}\left(\mathrm{RuO}_{2}\right)$ to $-4.12 \mathrm{eV}$ with $\mathrm{W}$ and Er introduction. And the gap between $\varepsilon_{\mathrm{p}}$ and Fermi level is obviously enlarged $^{28}$. This result indicates the covalency of $\mathrm{Ru}-\mathrm{O}$ bond is decreased by introduction of $\mathrm{W}$ and $\mathrm{Er}^{37}$. Therefore, in $\mathrm{W}_{0.2} \mathrm{Er}_{0.1} \mathrm{Ru}_{0.7} \mathrm{O}_{2-\delta}$, the direct $\mathrm{O}-\mathrm{O}$ coupling on $\mathrm{O} 2 p$ states above the Fermi level will be not thermodynamically favored, which could be seen from $\Delta G_{2}$ for formation of $\mathrm{OH}^{*}$ (Fig. $2 \mathrm{~b}$, right). This result will make $\Delta G$ for formation of $\mathrm{V}_{\mathrm{O}}$ higher than that of $\mathrm{RuO}_{2}$ (Fig. 2b, left). Further, the DFT results also reveal $\Delta G$ for formation of $\mathrm{V}_{\mathrm{O}}$ at the pyramid vertex of $\mathrm{W}_{0.2} \mathrm{Er}_{0.1} \mathrm{Ru}_{0.7}$ $\mathrm{O}_{2-\delta}$ shifts from lower energy band of $0.67 \mathrm{eV}\left(\mathrm{RuO}_{2}\right)$ to higher energy band of $2.29 \mathrm{eV}$ (Fig. 2c). These results indicate $\mathrm{W}$ and $\mathrm{Er}$ could effectively enhance the energy for formation of $\mathrm{V}_{\mathrm{O}}$ in $\mathrm{W}_{0.2} \mathrm{Er}_{0.1} \mathrm{Ru}_{0.7} \mathrm{O}_{2-\delta}$ toward acidic OER. Therefore, the dissolution of $\mathrm{Ru}$ in acidic electrolyte will be suppressed. Moreover, Bader charge analyses also prove the downshift of $p$ band centers, resulting in the negative charge of the lattice $\mathrm{O}$ (Supplementary Fig. 2). Consequently, this electronic state could effectively enhance $\Delta G$ for the formation of $\mathrm{V}_{\mathrm{O}}$ and suppress the lattice $\mathrm{O}$ binding with oxygen intermediates to release $\mathrm{O}_{2}$. Besides that, the corresponding model structures were established for oxidation of lattice oxygen on surface of (110) in $\mathrm{W}_{0.2} \mathrm{Er}_{0.1} \mathrm{Ru}_{0.7} \mathrm{O}_{2-\delta}$ (Supplementary Fig. 3). However, the $\mathrm{OH}^{*}$ adsorbed on $\mathrm{W}_{0.2} \mathrm{Er}_{0.1} \mathrm{Ru}_{0.7} \mathrm{O}_{2-\delta}$ was not stable and transferred to $\mathrm{Ru}, \mathrm{W}$, or $\mathrm{Er}$ sites after optimization of the models (step II in Fig. 1c and Supplementary Fig. 3). Therefore, the lattice oxygen in $\mathrm{W}_{0.2} \mathrm{Er}_{0.1} \mathrm{Ru}_{0.7} \mathrm{O}_{2-\delta}$ will not participate in acidic OER process. This result also confirmed that introducing $\mathrm{W}$ and Er into $\mathrm{RuO}_{2}$ could suppress the dissolution rate of $\mathrm{Ru}$.

DFT calculations were then performed to rationalize the acidic OER performance (Fig. 2d and Supplementary Figs. 4-12). As also motived by the experimental results of synthesized samples, all the models were established based on (110) surface. Besides that, the solvation was not considered in our calculation because the DFT was intended to understand trends when doping the 
a
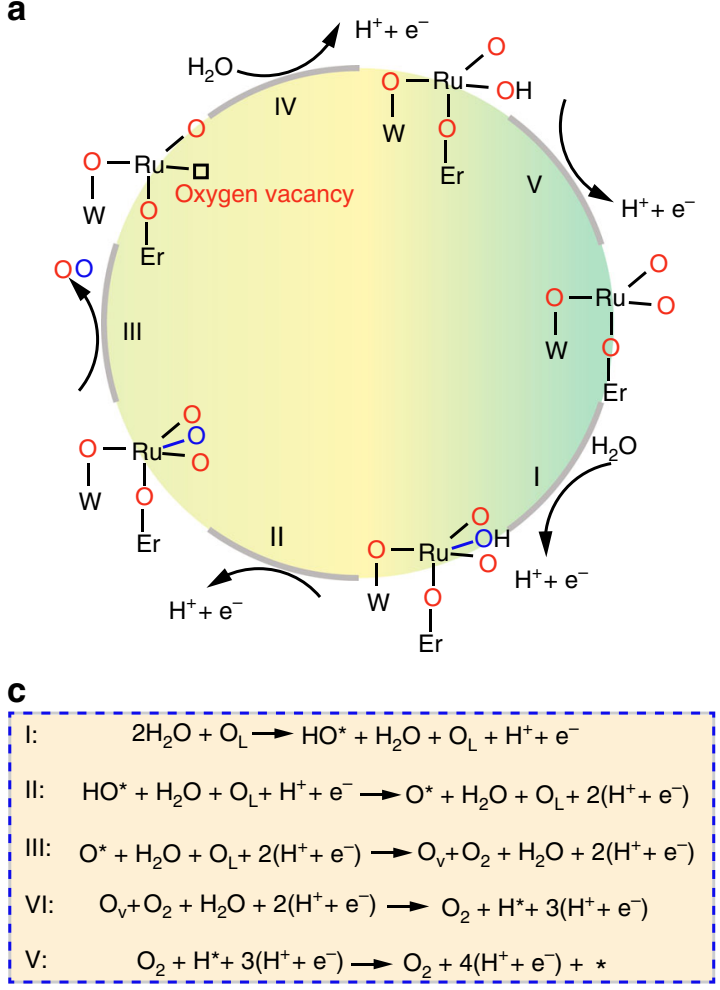

b
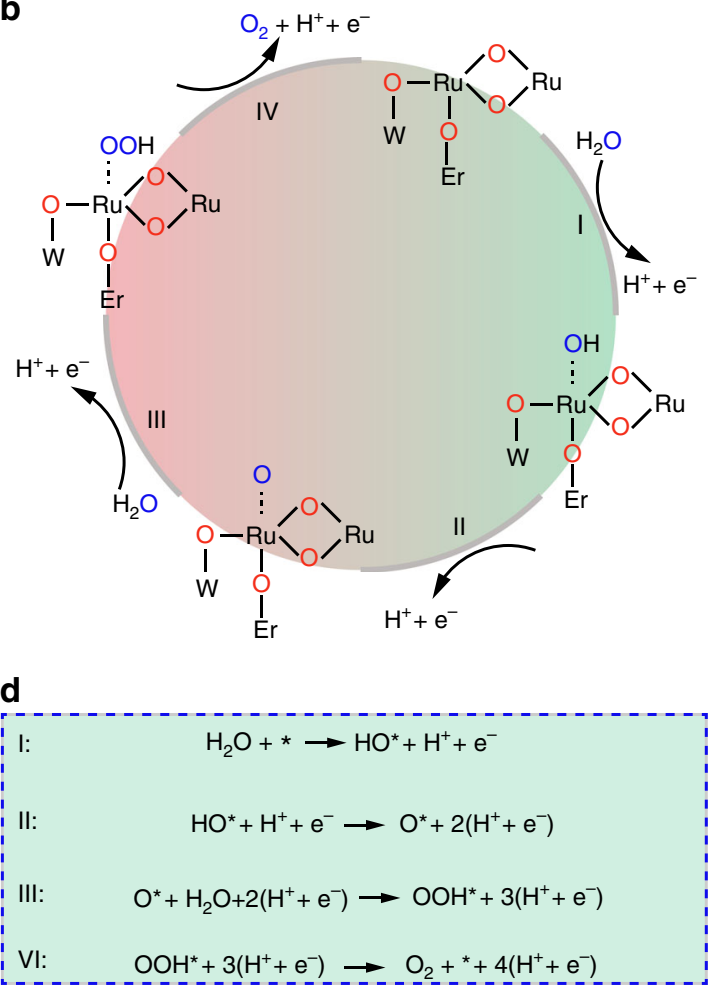

Fig. 1 Schematic illustration of $\mathbf{W}_{\mathbf{0 . 2}} \mathbf{E r}_{\mathbf{0 . 1}} \mathbf{R u}_{\mathbf{0 . 7}} \mathbf{O}_{\mathbf{2}-\boldsymbol{\delta}}$ toward acidic OER. a The illustration of lattice oxygen oxidation way of $\mathrm{W}_{0.2} \mathrm{Er}_{0.1} \mathrm{Ru}_{0.7} \mathrm{O}_{2-\delta}$ toward acidic OER. $\mathbf{b}$ The illustration of adsorbate evolution way of $\mathrm{W}_{0.2} \mathrm{Er}_{0.1} \mathrm{Ru}_{0.7} \mathrm{O}_{2-\delta}$ toward acidic OER. $\mathbf{c}$ the reaction paths of $\mathrm{W}_{0.2} \mathrm{Er}_{0.1} \mathrm{Ru}_{0.7} \mathrm{O}_{2-\delta}$ for lattice oxygen oxidation. $\mathbf{d}$ the reaction paths of $\mathrm{W}_{0.2} \mathrm{Er}_{0.1} \mathrm{Ru}_{0.7} \mathrm{O}_{2-\delta}$ for adsorbate evolution oxidation ( ${ }^{*}$ represents the surface-bound species on

$\mathrm{W}_{0.2} \mathrm{Er}_{0.1} \mathrm{Ru}_{0.7} \mathrm{O}_{2-\delta}$.

$\mathrm{RuO}_{2}$ surface with foreign metal atoms. All potential determining steps (PDS) for these designed samples were between $\mathrm{OOH}^{*}$ and $\mathrm{O}^{*}$. The calculated $\Delta G$ for PDS followed the order of $\mathrm{W}_{0.2} \mathrm{Er}_{0.1} \mathrm{Ru}_{0.7} \mathrm{O}_{2-\delta-1} \quad(0.53 \mathrm{eV})<\mathrm{W}_{0.2} \mathrm{Ru}_{0.8} \mathrm{O}_{2-\delta-1} \quad(0.6 \mathrm{eV})<$ $\mathrm{Er}_{0.1} \mathrm{Ru}_{0.9} \mathrm{O}_{2-\delta-1}(0.72 \mathrm{eV})<\mathrm{RuO}_{2}(0.79 \mathrm{eV})$ (Fig. 2d and Supplementary Figs. 4-6), revealing that simultaneously doping $\mathrm{W}$ and Er could reduce energy barriers for boosting activities. This phenomenon also agreed well with the upshift of $\mathrm{Ru} 4 d$ band centers, which tuned the adsorption energy of oxygen intermediates on active sites. Moreover, the surface of the prepared and established models for these $\mathrm{RuO}_{2}$-based materials was not bare anymore at $U>1.23 \mathrm{~V}$ vs. RHE. And there should be neighboring intermediates around active sites, which influenced on the energetics of the elementary processes in the OER (Supplementary Figs. 9-11). According to the calculations, the energy barrier for PDS significantly decreased (Supplementary Figs. 10 and 11), compared with the traditional models without considering the neighboring intermediates (Supplementary Figs. 4-6). Therefore, these results also indicated that the neighboring intermediates around active sites could also contribute to enhancing the activity of $\mathrm{W}_{0.2} \mathrm{Er}_{0.1} \mathrm{Ru}_{0.7} \mathrm{O}_{2-\delta-1}$ toward OER. Besides that, $\Delta G_{2}$ for formation of $\mathrm{OH}^{*}$ has always acted as a descriptor for indicating the activity trends of the modeled materials ${ }^{38}$. The scaling relation of $\Delta G_{2}$ and $\Delta G_{3}$ for formation of $\mathrm{OH}^{*}$ and $\mathrm{OOH}^{*}$ should be also coupled: $2.6 \mathrm{eV} \leq$ $\Delta G_{2}+\Delta G_{3} \leq 3.6 \mathrm{eV}^{39}$. As seen from the relationship of overpotential and $\Delta G_{2}$, the calculated $\Delta G_{2}$ for $\mathrm{W}_{0.2} \mathrm{Er}_{0.1} \mathrm{Ru}_{0.7} \mathrm{O}_{2-\delta-1}$ $(1.01 \mathrm{eV})$ was the apex of the volcano (Supplementary Fig. 12). Additionally, the calculated $\Delta G_{2}$ for $\mathrm{W}_{0.2} \mathrm{Er}_{0.1} \mathrm{Ru}_{0.7} \mathrm{O}_{2-\delta-1}(1.01$ $\mathrm{eV})$ was also close to the theoretical $\Delta G_{2}(1.23 \mathrm{eV})^{22}$. These results revealed that $\mathrm{W}_{0.2} \mathrm{Er}_{0.1} \mathrm{Ru}_{0.7} \mathrm{O}_{2-\delta-1}$ possessed the moderate $\Delta G_{2}$ among these structures toward acidic OER. According to above results, the co-doping of $\mathrm{W}$ and $\mathrm{Er}$ into $\mathrm{RuO}_{2}$ could effectively reduce generation of $\mathrm{V}_{\mathrm{O}}$ and soluble $\mathrm{Ru}^{x>4}$, which sufficiently enhance the acidic OER stabilities and activities.

Synthesis and characterization. To experimentally probe the predictions, $\mathrm{W}_{m} \mathrm{Er}_{n} \mathrm{Ru}_{1-m-n} \mathrm{O}_{2-\delta}$ nanosheets with various ratios were synthesized by a hydrothermal method, in which ethylenediaminetetraacetic acid (EDTA), ruthenium(III) acetate, $\mathrm{WCl}_{6}$, $\mathrm{ErCl}_{3}$, and citric acid were used as precursors (Fig. 3a). Supplementary Fig. 13 shows that these as-synthesized materials are of the rutile ruthenium oxides $\left(\mathrm{RuO}_{2}, \mathrm{PDF} \#: 40-1290\right)$ along with the dominant (110) peak. Transmission electron microscopy (TEM) exhibited that the prepared $\mathrm{W}_{m} \mathrm{Er}_{n} \mathrm{Ru}_{1-m-n} \mathrm{O}_{2-\delta}$ samples possessed the ultrathin nanosheet morphology (Fig. 3b, c, and Supplementary Figs. 14-19). The corresponding elemental mapping confirmed that Er, W, and Ru were uniformly distributed in these nanosheets (Fig. 3d). High-resolution TEM (HR-TEM), fast Fourier transform (FFT), and selected area electron diffraction (SAED) revealed that $\mathrm{W}_{0.2} \mathrm{Er}_{0.1} \mathrm{Ru}_{0.7} \mathrm{O}_{2-\delta}$ nanosheets possessed a face centered cubic (FCC) crystal face along (110) direction (Fig. 3e, f). The atomic ratios of $\mathrm{Ru}, \mathrm{W}$, and $\mathrm{Er}$ in these asprepared samples were analyzed by inductively coupled plasma mass spectrometry (ICP-MS). The results revealed the atomic ratio of these elements was close to the expected values (Supplementary Tables 1-6).

Oxidation state analysis. X-ray photoelectron spectra (XPS) was carried out on these prepared Ru-based nanosheet catalysts to analyze their compositions and chemical states (Supplementary Fig. 20). From Fig. $4 \mathrm{a}$, the $\mathrm{Ru} 3 d$ spectra for $\mathrm{RuO}_{2-\delta}, \mathrm{W}_{0.2} \mathrm{Ru}_{0.8} \mathrm{O}_{2-\delta}$, $\mathrm{Er}_{0.1} \mathrm{Ru}_{0.9} \mathrm{O}_{2-\delta}$, and $\mathrm{W}_{0.2} \mathrm{Er}_{0.1} \mathrm{Ru}_{0.7} \mathrm{O}_{2-\delta}$ could be deconvoluted into 
a
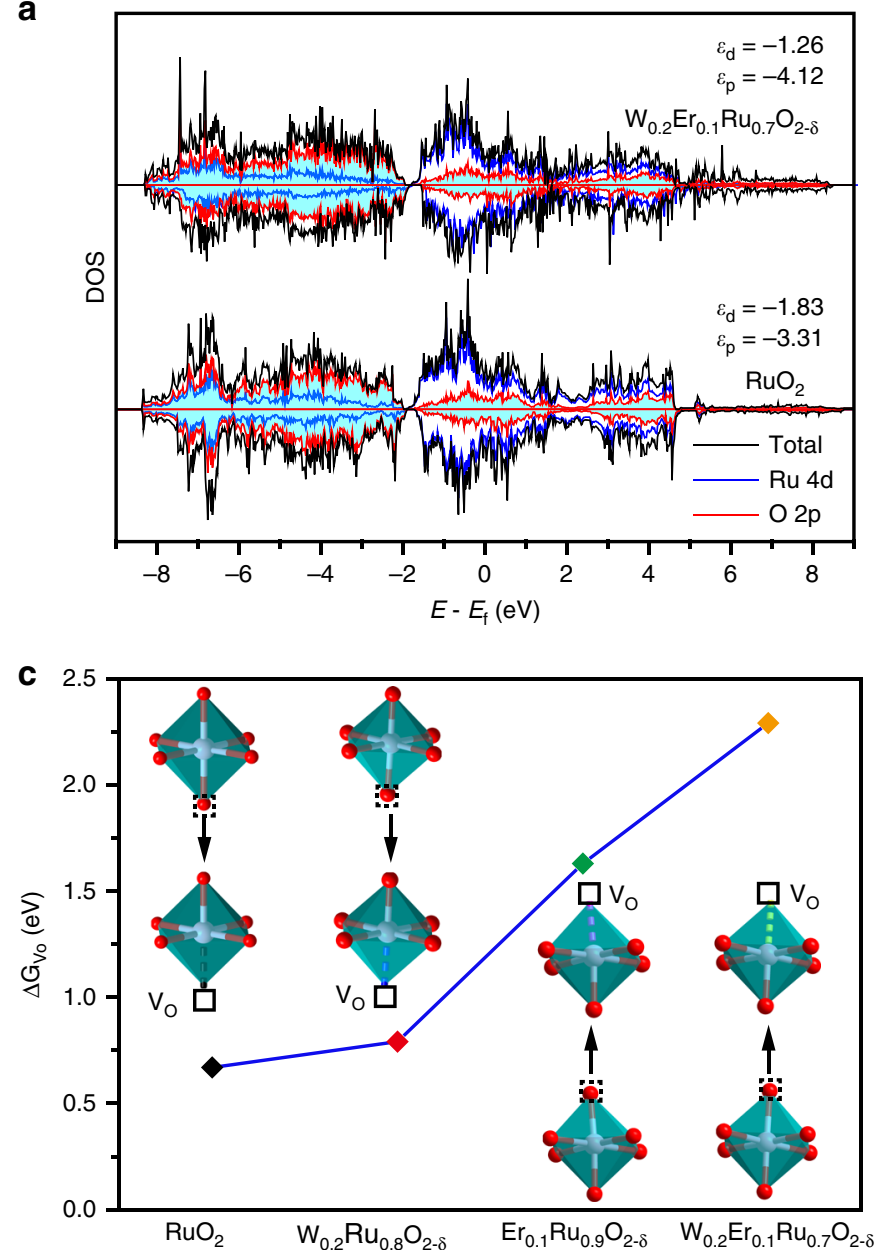

b

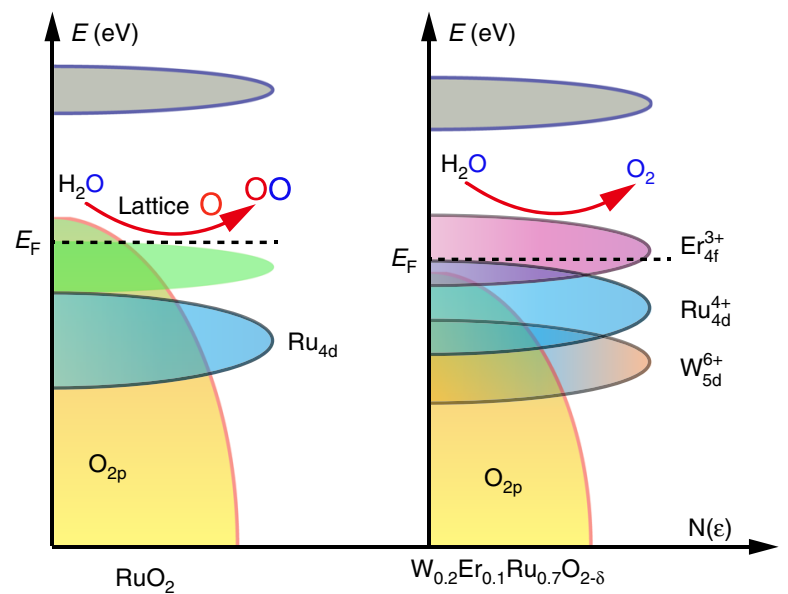

d

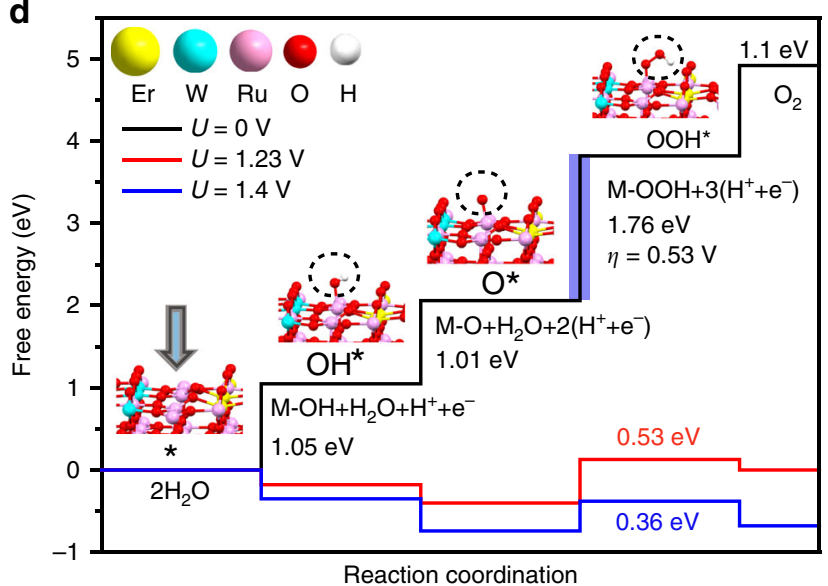

Fig. 2 DFT for $\mathbf{R u O}_{\mathbf{2}}$ and $\mathbf{W}_{\mathbf{0 . 2}} \mathrm{Er}_{\mathbf{0 . 1}} \mathbf{R u}_{\mathbf{0 . 7}} \mathbf{O}_{\mathbf{2}-\boldsymbol{\delta}}$ toward acidic OER. a DOS plots of Ru $4 d$ and O $2 p$ states in $\mathrm{RuO}_{2}$ and $\mathrm{W}_{0.2} \mathrm{Er}_{0.1} \mathrm{Ru}_{0.7} \mathrm{O}_{2-\delta-1}$. The dashed line means the Fermi level energy $\left(E_{\mathrm{F}}\right)$. b Schematic diagrams of rigid band models for $\mathrm{RuO}_{2}$ and $\mathrm{W}_{0.2} \mathrm{Er}_{0.1} \mathrm{Ru}_{0.7} \mathrm{O}_{2-\delta-1}$ toward acidic OER. $\mathbf{c}$ The calculated energy for formation of $\mathrm{V}_{\mathrm{O}}$ in different positions of $\mathrm{RuO}_{2}, \mathrm{~W}_{0.2} \mathrm{Ru}_{0.8} \mathrm{O}_{2-\delta-1}, \mathrm{Er}_{0.1} \mathrm{Ru}_{0.9} \mathrm{O}_{2-\delta-1}$, and $\mathrm{W}_{0.2} \mathrm{Er}_{0.1} \mathrm{Ru}_{0.7} \mathrm{O}_{2-\delta-1}$. d The calculated energy barriers diagram for $\mathrm{W}_{0.2} \mathrm{Er}_{0.1} \mathrm{Ru}_{0.7} \mathrm{O}_{2-\delta-1}$. The corresponding models of $\mathrm{W}_{0.2} \mathrm{Er}_{0.1} \mathrm{Ru}_{0.7} \mathrm{O}_{2-\delta-1}$ to oxygen intermediates such as $\mathrm{OH}^{\star}, \mathrm{O}^{\star}$ as well as $\mathrm{OOH}^{\star}(\mathrm{The}$ number 1 or other numeral represents different established models for these structures).

two kinds of doublets. The binding energies of lower energy couples situated at $280.6\left(\mathrm{Ru} 3 d_{5 / 2}\right)$ and $284.8 \mathrm{eV}\left(\mathrm{Ru} 3 d_{3 / 2}\right)$ were, respectively, attributed to $\mathrm{Ru}^{x<4}$ and $\mathrm{Ru}^{4+3,40}$. Simultaneously, the higher energy couples situated at 282.2 and $286.7 \mathrm{eV}$ were, respectively, ascribed to the satellite peaks. The average area and intensity ratios for $\mathrm{Ru} 3 d_{3 / 2}$ and $\mathrm{Ru} 3 d_{5 / 2}$ were, respectively, higher (2:1.2) and lower $(2: 3.3)$ than the expected value of $2: 3$. This should be ascribed to the fact that the $\mathrm{C} 1 s$ peak was coincided with $\mathrm{Ru} 3 d^{41}$. The $\mathrm{Ru} 3 d_{3 / 2}$ for $\mathrm{W}_{0.2} \mathrm{Er}_{0.1} \mathrm{Ru}_{0.7} \mathrm{O}_{2-\delta}$ was negatively shifted $(0.15 \mathrm{eV})$ compared with those of $\mathrm{RuO}_{2-\delta}, \mathrm{W}_{0.2} \mathrm{Ru}_{0.8} \mathrm{O}_{2-\delta}$, and $\mathrm{Er}_{0.1} \mathrm{Ru}_{0.9} \mathrm{O}_{2-\delta}$, demonstrating that $\mathrm{Ru}$ in $\mathrm{W}_{0.2} \mathrm{Er}_{0.1} \mathrm{Ru}_{0.7} \mathrm{O}_{2-\delta}$ was in a little lower valence state than $\mathrm{Ru}^{4+}$. For $\mathrm{W} 4 f$, the binding energies were deconvoluted into $\mathrm{W}$ $4 f_{5 / 2}(37.4 \mathrm{eV})$ and $\mathrm{W} 4 f_{7 / 2}(35.5 \mathrm{eV})$, indicating the element of $\mathrm{W}$ was in an valence state of $\mathrm{W}^{6+}$ (Fig. $\left.4 \mathrm{~b}\right)^{42}$. Similarly, the average area and intensity ratios for $\mathrm{W} 4 f_{5 / 2}$ and $\mathrm{W} 4 f_{7 / 2}$ doublet were, respectively, 15:17 and 9:10, which were close to the expected value of 3:4. Moreover, compared with $\mathrm{W}_{0.2} \mathrm{Ru}_{0.8} \mathrm{O}_{2-\delta}$, the binding energies of $\mathrm{W} 4 f_{5 / 2}$ and $\mathrm{W} 4 f_{7 / 2}$ for $\mathrm{W}_{0.2} \mathrm{Er}_{0.1} \mathrm{Ru}_{0.7} \mathrm{O}_{2-\delta}$ were, respectively, negatively shifted with 0.74 and $0.60 \mathrm{eV}$ (Fig. $4 \mathrm{~b}$ ), confirming that $\mathrm{W}$ in $\mathrm{W}_{0.2} \mathrm{Er}_{0.1} \mathrm{Ru}_{0.7} \mathrm{O}_{2-\delta}$ exhibited a lower valence state than $\mathrm{W}^{6+}$. From Fig. $3 c$, the binding energies for Er $4 d$ could be fitted with two peaks, which should be, respectively, assigned to $\operatorname{Er} 4 d(170.0 \mathrm{eV})$ and $\operatorname{Er} 4 d_{5 / 2}(168.5 \mathrm{eV})$, revealing the Er element in these samples were in $\mathrm{Er}^{3+}$ valence state $^{43}$. Interestingly, as compared with
$\mathrm{Er}_{0.1} \mathrm{Ru}_{0.9} \mathrm{O}_{2-\delta}$, the Er $4 d_{5 / 2}$ and $\mathrm{Er} 4 d$ for $\mathrm{W}_{0.2} \mathrm{Er}_{0.1} \mathrm{Ru}_{0.7} \mathrm{O}_{2-\delta}$ were, respectively, positively shifted with 0.20 and $0.47 \mathrm{eV}$ (Fig. 4c). This indicates that $\mathrm{Er}^{3+}$ in $\mathrm{W}_{0.2} \mathrm{Er}_{0.1} \mathrm{Ru}_{0.7} \mathrm{O}_{2-\delta}$ was a little more positively charged. Besides that, $\mathrm{O} 1 s$ peaks around at 532, 530.5, and $529.3 \mathrm{eV}$ are, respectively, confirmed as hydroxyl groups, lattice oxygen, and $\mathrm{M}-\mathrm{O}$ bonds. The lattice oxygen and $\mathrm{M}-\mathrm{O}$ bonds in $\mathrm{W}_{0.2} \mathrm{Er}_{0.1} \mathrm{Ru}_{0.7} \mathrm{O}_{2-\delta}, \mathrm{W}_{0.2} \mathrm{Ru}_{0.8} \mathrm{O}_{2-\delta}$, and $\mathrm{Er}_{0.1} \mathrm{Ru}_{0.9} \mathrm{O}_{2-\delta}$ nanosheets were slightly positive shifted compared with $\mathrm{RuO}_{2-\delta}$, respectively (Fig. 4d), indicating $\mathrm{O} 1 s$ was positively charged ${ }^{44}$. Through above analyses, it could be concluded that some electrons were transferred from $\mathrm{Er}$ to $\mathrm{Ru}$ and $\mathrm{W}$ through $\mathrm{O}$ in $\mathrm{W}_{0.2} \mathrm{Er}_{0.1} \mathrm{Ru}_{0.7} \mathrm{O}_{2-\delta}$, confirming the electronic interactions among $\mathrm{Ru}, \mathrm{W}, \mathrm{Er}$, and $\mathrm{O}^{45}$.

Electrochemical OER in acid electrolyte. To establish correlation between the electrocatalytic performances and the specific electronic structure, the OER activities of the prepared $\mathrm{W}_{m} \mathrm{Er}_{n}$ $\mathrm{Ru}_{1-m-n} \mathrm{O}_{2-\delta}$ nanosheets and $\mathrm{C}-\mathrm{RuO}_{2}$ were investigated in $0.5 \mathrm{M} \mathrm{H}_{2} \mathrm{SO}_{4}$ (Supplementary Figs. 21 and 22). The linear sweep voltammetry (LSV, scan rate: $5 \mathrm{mV} \mathrm{s}^{-1}$ ) was corrected with $i R$ and normalized with geometrical area, respectively. It was seen that the performances of prepared electrocatalysts followed an order of $\mathrm{W}_{0.2} \mathrm{Er}_{0.1} \mathrm{Ru}_{0.7} \mathrm{O}_{2-\delta}>\mathrm{Er}_{0.1} \mathrm{Ru}_{0.9} \mathrm{O}_{2-\delta}>\mathrm{W}_{0.2} \mathrm{Ru}_{0.8} \mathrm{O}_{2-\delta}$ nanosheets $>\mathrm{C}-\mathrm{RuO}_{2}$ NPs as shown in Fig. 6a. Simultaneously, 


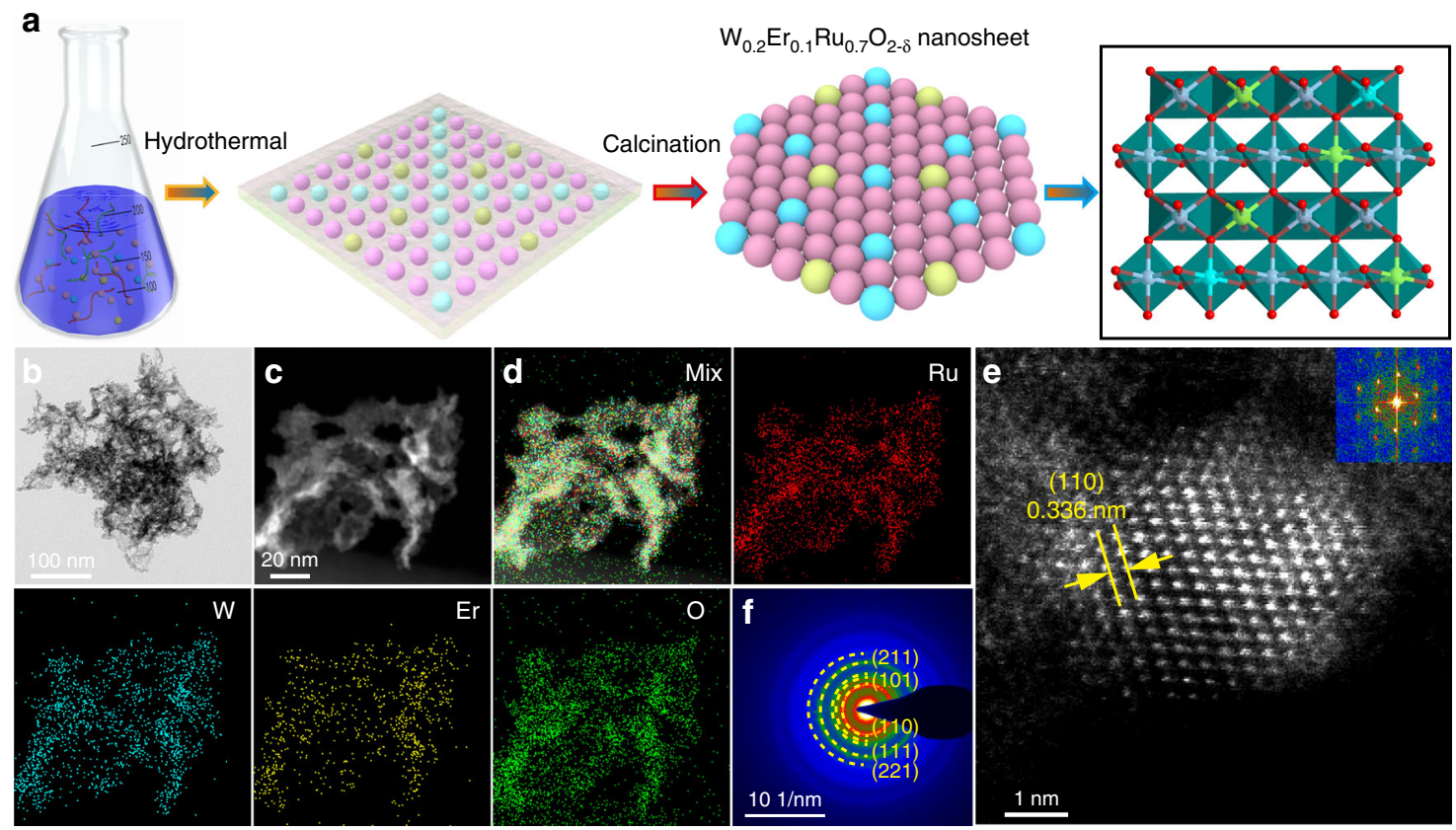

Fig. 3 The designing strategy and TEM characterization for the prepared $\mathbf{W}_{\mathbf{0 . 2}} \mathbf{E r}_{\mathbf{0 . 1}} \mathbf{R} \mathbf{u}_{\mathbf{0} .7} \mathbf{O}_{\mathbf{2}-\delta}$ nanosheets. a Schematic route for synthesis of $\mathrm{W}_{0.2} \mathrm{Er}_{0.1} \mathrm{Ru}_{0.7} \mathrm{O}_{2-\delta}$ nanosheets. b TEM image, $\mathbf{c} \mathrm{HAADF}-\mathrm{TEM}$ image, $\mathbf{d}$ the corresponding elemental maps, e HR-TEM image (inset: Fourier transform analyses for $\mathrm{W}_{0.2} \mathrm{Er}_{0.1} \mathrm{Ru}_{0.7} \mathrm{O}_{2-\delta}$ ), and $\mathbf{f} \mathrm{SAED}$ image for the $\mathrm{W}_{0.2} \mathrm{Er}_{0.1} \mathrm{Ru}_{0.7} \mathrm{O}_{2-\delta}$ nanosheets.

the representative $\mathrm{W}_{0.2} \mathrm{Er}_{0.1} \mathrm{Ru}_{0.7} \mathrm{O}_{2-\delta}$ nanosheet exhibited a record performance toward OER with an overpotential $(\eta)$ as low as $168 \mathrm{mV}$ at $10 \mathrm{~mA} \mathrm{~cm}^{-2}$ (Fig. 6a), remarkably preceding other prepared $\mathrm{Ru}$-based nanosheets. Simultaneously, $\mathrm{W}_{0.2} \mathrm{Er}_{0.1} \mathrm{Ru}_{0.7} \mathrm{O}_{2-\delta}$ also exhibited the fastest reaction rate among these prepared samples with a small Tafel slope of $66.8 \mathrm{mV} \mathrm{dec}^{-1}$ (Fig. 6b). The current density of $\mathrm{W}_{0.2} \mathrm{Er}_{0.1} \mathrm{Ru}_{0.7} \mathrm{O}_{2-\delta}$ nanosheets could achieve $500 \mathrm{~mA} \mathrm{~cm}^{-2}$ at $\eta=275 \mathrm{mV}$, which was 28.6 -folds higher than that of $\mathrm{C}-\mathrm{RuO}_{2}$. It should be noted that the performance for the representative $\mathrm{W}_{0.2} \mathrm{Er}_{0.1} \mathrm{Ru}_{0.7} \mathrm{O}_{2-\delta}$ was also superior to those of the catalysts reported recently (Supplementary Table 9).

To reveal the origin of the performances for prepared samples, electrochemical double-layer capacitance $\left(C_{\mathrm{dl}}\right)$ was performed to measure the surface area and roughness factor $\left(R_{\mathrm{f}}\right)$ (Fig. $6 \mathrm{c}$ and Supplementary Figs. 23-27). Moreover, CV curves for these materials supported on glass carbon electrode were also measured to confirm $C_{\mathrm{dl}}$ (Supplementary Figs. 26 and 27). As listed in Supplementary Table 8 , the calculated $C_{\mathrm{dl}}, R_{\mathrm{f}}$, and surface area exhibited a similar trend as activity. $\mathrm{W}_{0.2} \mathrm{Ru}_{0.8} \mathrm{O}_{2-\delta}, \mathrm{Er}_{0.1} \mathrm{Ru}_{0.9} \mathrm{O}_{2-\delta}$, and $\mathrm{W}_{0.2} \mathrm{Er}_{0.1} \mathrm{Ru}_{0.7}$ $\mathrm{O}_{2-\delta}$ nanosheet structures revealed successively increased roughness compared with $\mathrm{RuO}_{2-\delta}$ nanosheets. The representative $\mathrm{W}_{0.2} \mathrm{Er}_{0.1}$ $\mathrm{Ru}_{0.7} \mathrm{O}_{2-\delta}\left(1231.8 \mathrm{~m}^{2} \mathrm{~g}^{-1}\right)$ exhibited much larger surface area than $\mathrm{Er}_{0.1} \mathrm{Ru}_{0.9} \mathrm{O}_{2-\delta}\left(494.9 \mathrm{~m}^{2} \mathrm{~g}^{-1}\right), \mathrm{W}_{0.2} \mathrm{Ru}_{0.8} \mathrm{O}_{2-\delta}\left(326.3 \mathrm{~m}^{2} \mathrm{~g}^{-1}\right)$, and $\mathrm{RuO}_{2-\delta}\left(166.7 \mathrm{~m}^{2} \mathrm{~g}^{-1}\right)$, probably originating from more active sites exposure with co-doping of $\mathrm{W}$ and $\mathrm{Er}$ into $\mathrm{RuO}_{2}$ nanosheets (Supplementary Fig. 21d). The calculated specific activity followed an order of $\quad \mathrm{W}_{0.2} \mathrm{Er}_{0.1} \mathrm{Ru}_{0.7} \mathrm{O}_{2-\delta} \quad\left(1.23 \mathrm{~mA} \mathrm{~cm}^{-2}{ }_{\text {ox }}\right)>\mathrm{W}_{0.2} \mathrm{Ru}_{0.8} \mathrm{O}_{2-\delta}$ $\left(1.16 \mathrm{~mA} \mathrm{~cm}^{-2}{ }_{\text {ox }}\right)>\mathrm{Er}_{0.1} \mathrm{Ru}_{0.9} \mathrm{O}_{2-\delta} \quad\left(1.15 \mathrm{~mA} \mathrm{~cm}^{-2}{ }_{\text {ox }}\right)>\mathrm{RuO}_{2-\delta}$ $\left(0.98 \mathrm{~mA} \mathrm{~cm}^{-2}{ }_{\text {ox }}\right)>\mathrm{C}_{-}-\mathrm{RuO}_{2} \quad\left(0.50 \mathrm{~mA} \mathrm{~cm}^{-2}{ }_{\text {ox }}\right)$. Simultaneously, $\mathrm{W}_{0.2} \mathrm{Er}_{0.1} \mathrm{Ru}_{0.7} \mathrm{O}_{2-\delta}$ also possessed the highest mass activity of $1518.6 \mathrm{Ag} \mathrm{g}_{\text {ox }}^{-1}$, which was $2.7,5.8$, and 28.5 -folds higher than $\mathrm{Er}_{0.1} \mathrm{Ru}_{0.9} \mathrm{O}_{2-\delta}, \mathrm{W}_{0.2} \mathrm{Ru}_{0.8} \mathrm{O}_{2-\delta}$, and $\mathrm{C}-\mathrm{RuO}_{2}$, respectively (Supplementary Fig. 21d). The highest specific and mass activities for $\mathrm{W}_{0.2} \mathrm{Er}_{0.1} \mathrm{Ru}_{0.7} \mathrm{O}_{2-\delta}$ among these samples indicated the highest intrinsic activity of $\mathrm{W}_{0.2} \mathrm{Er}_{0.1} \mathrm{Ru}_{0.7} \mathrm{O}_{2-\delta}$.

Nyquist plots in Fig. $6 \mathrm{~d}$ were applied to fit the equivalent circuit diagram for the electrochemical impedance spectroscopy, revealing the reaction impendence between the electrode and solution. Figure $6 \mathrm{~d}$ shows that the charge-transfer resistance $\left(R_{\mathrm{ct}}\right)$ for $\mathrm{W}_{0.2} \mathrm{Er}_{0.1} \mathrm{Ru}_{0.7} \mathrm{O}_{2-\delta}$ was $3.3 \Omega$, which was much smaller than those of $\mathrm{Er}_{0.1} \mathrm{Ru}_{0.9} \mathrm{O}_{2-\delta}(13.8 \Omega), \mathrm{W}_{0.2} \mathrm{Ru}_{0.8} \mathrm{O}_{2-\delta}(20.2 \Omega)$, and $\mathrm{RuO}_{2-\delta}(50.8 \Omega)$. These results further confirmed the co-doping of $\mathrm{W}$ and Er into $\mathrm{RuO}_{2-\delta}$ nanosheets enhanced the intrinsic OER property of the samples. Additionally, Faraday efficiency for OER on $\mathrm{W}_{0.2} \mathrm{Er}_{0.1} \mathrm{Ru}_{0.7} \mathrm{O}_{2-\delta}$ could reach $99.5 \%$, indicating the current mainly came from OER as shown in Supplementary Fig. 28.

Stability for acidic OER and PEM. The stability in acidic electrolyte is a critical factor to evaluate the performances of OER electrocatalysts due to highly oxidative operating conditions and corrosive electrolytes. The stability of $\mathrm{W}_{0.2} \mathrm{Er}_{0.1} \mathrm{Ru}_{0.7} \mathrm{O}_{2-\delta}$ could be assessed by $\Delta \eta=\eta_{\text {final }}-\eta_{\text {initial }}$, the gap between the final and initial overpotential $(\eta)$ can be calculated from a chronopotentiometric test of $10 \mathrm{~mA} \mathrm{~cm}^{-2}$. From Fig. $7 \mathrm{a}$, the chronopotentometric line exhibited a highly durable stability for $250 \mathrm{~h}$ with a small increase of $\Delta \eta=83 \mathrm{mV}$, indicating the excellent stability of $\mathrm{W}_{0.2} \mathrm{Er}_{0.1} \mathrm{Ru}_{0.7} \mathrm{O}_{2-\delta}$ (Fig. $7 \mathrm{~b}$ and Supplementary Table 9). Remarkably, from 250 to $500 \mathrm{~h}$ during the stability test, the operation ran stably with a tiny increase of $\Delta \eta=5 \mathrm{mV}$, confirming the durable properties of $\mathrm{W}_{0.2} \mathrm{Er}_{0.1} \mathrm{Ru}_{0.7} \mathrm{O}_{2-\delta}$ in acidic electrolyte. Besides that, the stability of $\mathrm{W}_{0.2} \mathrm{Er}_{0.1} \mathrm{Ru}_{0.7} \mathrm{O}_{2-\delta}$ loaded on glass carbon electrode also revealed the durable stability in acidic electrolyte (Supplementary Fig. 29). As a contrast, the C$\mathrm{RuO}_{2}$ could only run $24 \mathrm{~h}$ with the large loss of $\Delta \eta=615 \mathrm{mV}$ (Supplementary Fig. 30). To confirm the fixation of $\mathrm{Ru}$ in $\mathrm{W}_{0.2} \mathrm{Er}_{0.1} \mathrm{Ru}_{0.7} \mathrm{O}_{2-\delta}$, ICP-MS was performed to analyze the concentration of the dissolved $\mathrm{W}, \mathrm{Er}$, and $\mathrm{Ru}$ in the solution during the $500 \mathrm{~h}$ stability test at an interval of $100 \mathrm{~h}$ (Fig. 7c). The results of ICP-MS revealed that the Ru cations in the solution were $<12$ ppb after $500 \mathrm{~h}$ (Supplementary Tables 10-18). More significantly, $\mathrm{W}_{0.2} \mathrm{Er}_{0.1} \mathrm{Ru}_{0.7} \mathrm{O}_{2-\delta}$ as anodic electrocatalyst could also operate steadily for $120 \mathrm{~h}$ at high current of $100 \mathrm{~mA} \mathrm{~cm}^{-2}$ in acidic PEM (Fig. 7d, e).

Charge redistribution of $\mathrm{W}_{0.2} \mathrm{Er}_{0.1} \mathrm{Ru}_{0.7} \mathrm{O}_{2-\delta}$ for the longdurable acidic OER stability. To prove the highly improved 

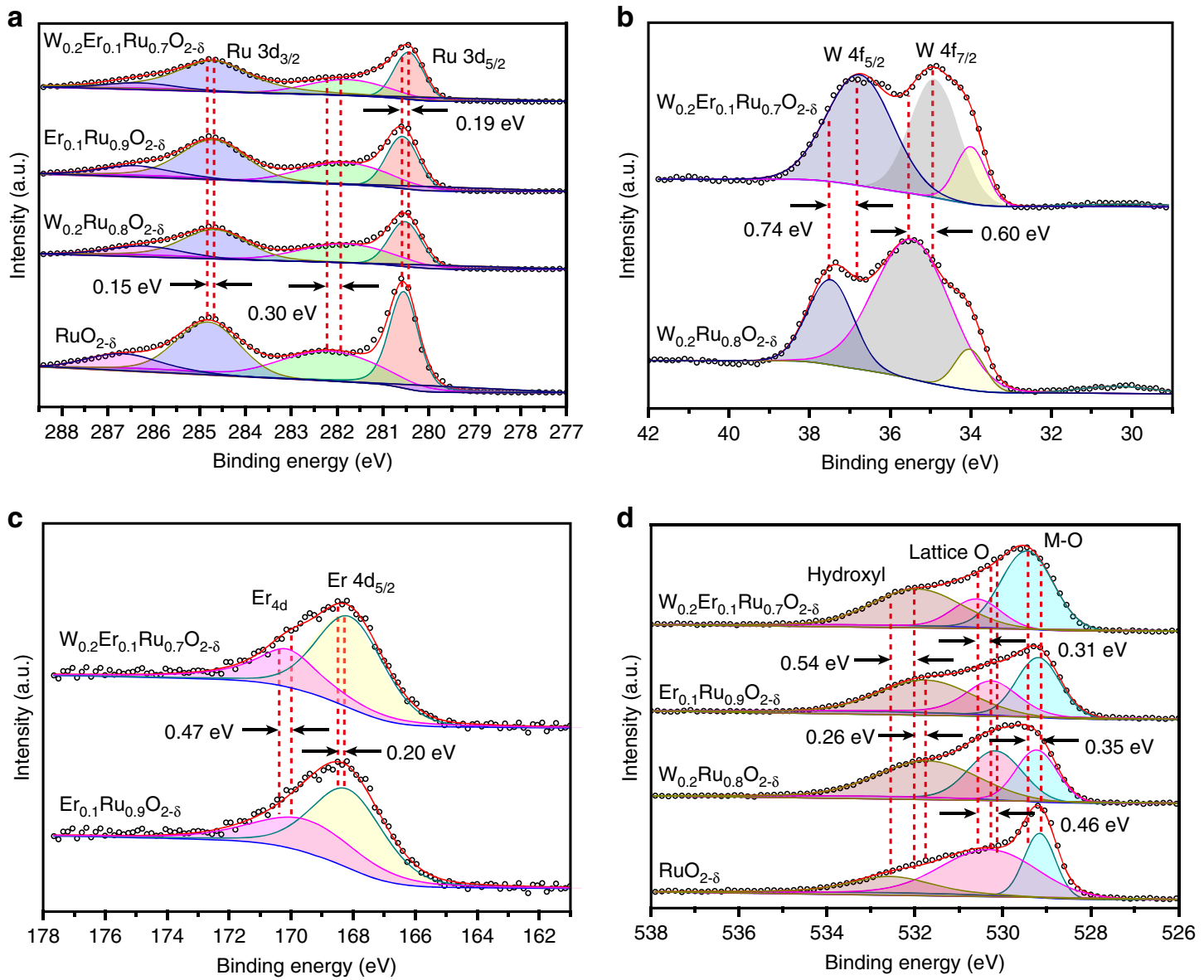

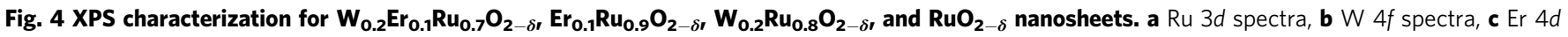
spectra, $\mathbf{d} \mathrm{O}$ 1s spectra for the prepared $\mathrm{W}_{0.2} \mathrm{Er}_{0.1} \mathrm{Ru}_{0.7} \mathrm{O}_{2-\delta 1} \mathrm{Er}_{0.1} \mathrm{Ru}_{0.9} \mathrm{O}_{2-\delta 1} \mathrm{~W}_{0.2} \mathrm{Ru}_{0.8} \mathrm{O}_{2-\delta \prime}$ and $\mathrm{RuO}_{2-\delta}$ nanosheets. In order to precisely analyze the valance state of $\mathrm{Ru}, \mathrm{X}$-ray absorption near-edge spectroscopy (XANES) was applied to characterize $\mathrm{RuO}_{2-\delta}$ and $\mathrm{W}_{0.2} \mathrm{Er}_{0.1} \mathrm{Ru}_{0.7} \mathrm{O}_{2-\delta}$. $\mathrm{Ru}_{0}$ foil and $\mathrm{C}$ - $\mathrm{RuO}_{2}$ were employed as reference materials ${ }^{3,18}$. Compared with Ru K-edge position of Ru foil, the $\mathrm{C}-\mathrm{RuO}_{2}, \mathrm{RuO}_{2-\delta}$, and $\mathrm{W}_{0.2} \mathrm{Er}_{0.1} \mathrm{Ru}_{0.7} \mathrm{O}_{2-\delta}$ all shifted to higher energy, resulting from the Ru-O bonds in these materials (Fig. 5a). Additionally, the Ru K-edge spectra in Fig. 5a showed the adsorption energy of the prepared $\mathrm{RuO}_{2-\delta}$ and $\mathrm{W}_{0.2} \mathrm{Er}_{0.1} \mathrm{Ru}_{0.7} \mathrm{O}_{2-\delta}$ were different from that for $\mathrm{C}-\mathrm{RuO}_{2}$. This result mainly resulted from the fact that $\mathrm{Ru}$ valence state in $\mathrm{RuO} \mathrm{O}_{2-\delta}$ and $\mathrm{W}_{0.2} \mathrm{Er}_{0.1} \mathrm{Ru}_{0.7} \mathrm{O}_{2-\delta}$ were mainly dominated $\mathrm{Ru}^{4+}$ accompanied with $\mathrm{Ru}^{x+}(x<4)^{3}$. Simultaneously, compared with adsorption energy of $\mathrm{RuO}_{2-\delta}$, the adsorption energy for $\mathrm{W}_{0.2} \mathrm{Er}_{0.1} \mathrm{Ru}_{0.7} \mathrm{O}_{2-\delta}$ shifted to lower energy region, indicating that $\mathrm{Ru}$ valence state in $\mathrm{W}_{0.2} \mathrm{Er}_{0.1} \mathrm{Ru}_{0.7} \mathrm{O}_{2-\delta}$ was a little lower than that in $\mathrm{RuO}_{2-\delta}$ due to introduction of $\mathrm{W}$ and Er. Additionally, the adsorption energy $\left(E_{0}\right)$ for $\mathrm{RuO}_{2-\delta}(22,119.99 \mathrm{eV})$ was also a little higher than that for $\mathrm{W}_{0.2} \mathrm{Er}_{0.1} \mathrm{Ru}_{0.7} \mathrm{O}_{2-\delta}(22,118.92 \mathrm{eV})$. These results were consistent with the valence state analysis in XPS. Furthermore, extended X-ray absorption fine structure (EXAFS) with Fourier transform as well as its counterpart ( $k^{3}$-weighted EXAFS) was applied to analyze the structure of $\mathrm{RuO}_{2-\delta}$ and $\mathrm{W}_{0.2} \mathrm{Er}_{0.1} \mathrm{Ru}_{0.7} \mathrm{O}_{2-\delta}$ (Fig. 5b). Compared with the bond of $\mathrm{Ru}-\mathrm{Ru}$ in $\mathrm{Ru}$ foil $\left(2.68 \AA\right.$ ), $\mathrm{W}_{0.2} \mathrm{Er}_{0.1} \mathrm{Ru}_{0.7} \mathrm{O}_{2-\delta}$ exhibited a slightly longer interatomic distance $\left(2.71 \AA\right.$ ), which could be related with the strained effect in $\mathrm{HRTEM}^{3}$ (Supplementary Table 7). Additionally, the Ru-Ru and Ru-O bonds in RuO ${ }_{2-\delta}$ and $\mathrm{W}_{0.2} \mathrm{Er}_{0.1} \mathrm{Ru}_{0.7} \mathrm{O}_{2-\delta}$ showed different interatomic distances is due to the existence of lower $\mathrm{Ru}^{x<4}$ valence state, compared with that in $\mathrm{C}-\mathrm{RuO}_{2}$ (3.12 and $3.56 \AA$ ). Besides that, the different $\mathrm{Ru}-\mathrm{Ru}, \mathrm{Ru}-\mathrm{O}$ bonds between $\mathrm{RuO}_{2-\delta}$ and $\mathrm{W}_{0.2} \mathrm{Er}_{0.1} \mathrm{Ru}_{0.7} \mathrm{O}_{2-\delta}$ should be related with introducing $\mathrm{W}$ and $\mathrm{Er}$ into $\mathrm{RuO} \mathrm{O}_{2-\delta}$. Furthermore, wavelet transform (WT) for Ru K-edge EXAFS in Fig. $5 \mathrm{c}-\mathrm{f}$ was applied to exhibit the length changes of Ru-Ru and Ru-O bonds in

$\mathrm{W}_{0.2} \mathrm{Er}_{0.1} \mathrm{Ru}_{0.7} \mathrm{O}_{2-\delta}$. The intensities at $\approx 6.5 \AA^{-1}$ increased gradually, indicating the $\mathrm{Ru}^{x<4}$ had strong influence on $\mathrm{W}_{0.2} \mathrm{Er}_{0.1} \mathrm{Ru}_{0.7} \mathrm{O}_{2-\delta}$ compared with that for $\mathrm{C}-\mathrm{RuO}_{2}$. Besides that, compared with $\mathrm{RuO}_{2-\delta}$, the intensities changed slightly at $\approx 13.5 \AA^{-1}$ in $\mathrm{W}_{0.2} \mathrm{Er}_{0.1} \mathrm{Ru}_{0.7} \mathrm{O}_{2-\delta}$ is due to the coordination of Ru-W/Er .

dissolution and oxidation resistance of $\mathrm{W}_{0.2} \mathrm{Er}_{0.1} \mathrm{Ru}_{0.7} \mathrm{O}_{2-\delta}$ toward OER in acidic electrolyte, the chemical states for $\mathrm{Ru}, \mathrm{W}, \mathrm{Er}$, and $\mathrm{O}$ in $\mathrm{W}_{0.2} \mathrm{Er}_{0.1} \mathrm{Ru}_{0.7} \mathrm{O}_{2-\delta}$ after the acidic OER measurement were further investigated and compared with these elements before OER, respectively (Fig. 8). The states of $\mathrm{W}_{0.2} \mathrm{Er}_{0.1} \mathrm{Ru}_{0.7} \mathrm{O}_{2-\delta}$ after the $500 \mathrm{~h}$ stability test were analyzed by XPS. For Ru $3 d$, the peaks at $284.8 \mathrm{eV}$ for $\mathrm{Ru} 3 d_{3 / 2}$ was not obviously positively or negatively shifted as compared with that of the sample before OER test, suggesting that the valence of active sites $\mathrm{Ru}$ remained $\mathrm{Ru}^{4+}$ during OER test (Fig. 8a). Simultaneously, the peak at $280.6 \mathrm{eV}\left(\mathrm{Ru} 3 d_{5 / 2}\right)$ disappeared, indicating that the $\mathrm{Ru}^{x<4}$ were all oxidized to $\mathrm{Ru}^{4+}$.

Besides that, $\mathrm{Ru}$ valence state in $\mathrm{W}_{0.2} \mathrm{Er}_{0.1} \mathrm{Ru}_{0.7} \mathrm{O}_{2-\delta}$ after OER was also characterized with both XANES and EXAFS (Supplementary
Fig. 31). $\mathrm{W}_{0.2} \mathrm{Er}_{0.1} \mathrm{Ru}_{0.7} \mathrm{O}_{2-\delta}$ showed similar adsorption energy with that for $\mathrm{C}-\mathrm{RuO}_{2}$, indicating $\mathrm{Ru}$ stayed $\mathrm{Ru}^{4+}$. Simultaneously, compared with adsorption energy of $\mathrm{W}_{0.2} \mathrm{Er}_{0.1} \mathrm{Ru}_{0.7} \mathrm{O}_{2-\delta}$ before OER, adsorption energy of $\mathrm{W}_{0.2} \mathrm{Er}_{0.1} \mathrm{Ru}_{0.7} \mathrm{O}_{2-\delta}$ after OER shifted to higher energy, implying $\mathrm{Ru}^{x<4}$ were all oxidized to $\mathrm{Ru}^{4+}$. This result also implied that there was no $\mathrm{RuO}_{4}$ generation during acidic OER. Moreover, EXAFS spectra exhibited that the $\mathrm{Ru}-\mathrm{Ru}$ bond $(2.71 \AA)$ in $\mathrm{W}_{0.2} \mathrm{Er}_{0.1} \mathrm{Ru}_{0.7} \mathrm{O}_{2-\delta}$ disappeared after OER, indicating that the $\mathrm{Ru}^{x<4}$ were oxidized to $\mathrm{Ru}^{4+}$ (Supplementary Table 19). Simultaneously, the $\mathrm{Ru}-\mathrm{Ru}, \mathrm{Ru}-\mathrm{O}, \mathrm{Ru}-\mathrm{W} / \mathrm{Er}$ bonds in $\mathrm{W}_{0.2} \mathrm{Er}_{0.1}$ $\mathrm{Ru}_{0.7} \mathrm{O}_{2-\delta}$ after OER was very close to the $\mathrm{W}_{0.2} \mathrm{Er}_{0.1} \mathrm{Ru}_{0.7}$ $\mathrm{O}_{2-\delta}$, indicating the crystal structure was kept almost unchangeable, except for the lower $\mathrm{Ru}^{x<4}$. 

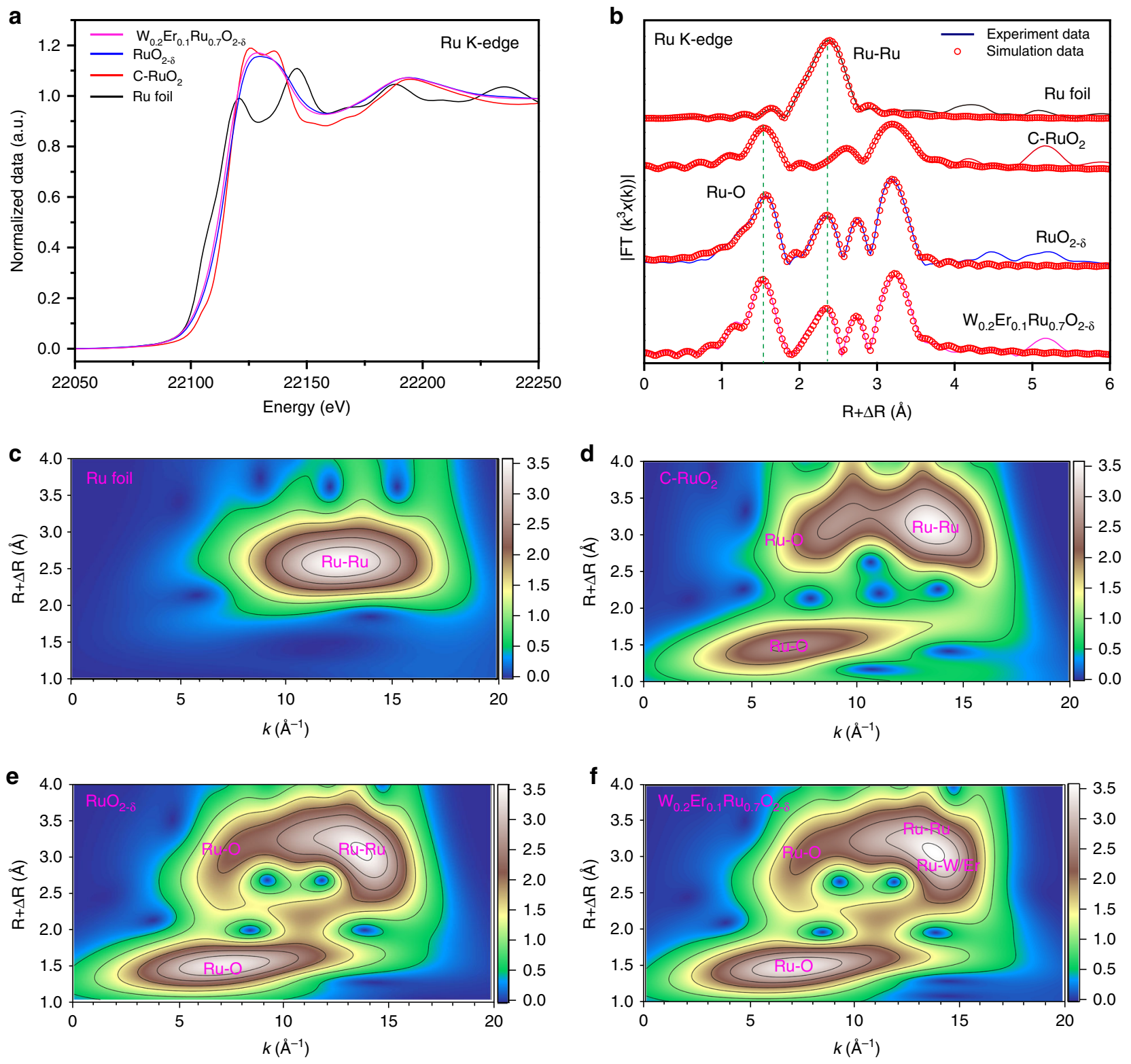

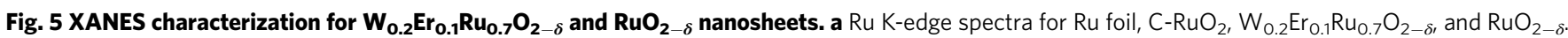
b FT-EXAFS spectra of Ru K-edge for Ru foil, $\mathrm{C}-\mathrm{RuO}_{2}, \mathrm{~W}_{0.2} \mathrm{Er}_{0.1} \mathrm{Ru}_{0.7} \mathrm{O}_{2-\delta}$, and $\mathrm{RuO}_{2-\delta}$. c-f WT-EXAFS of Ru foil, C-RuO $\mathrm{O}_{2}, \mathrm{RuO}_{2-\delta}$, and $\mathrm{W}_{0.2} \mathrm{Er}_{0.1} \mathrm{Ru}_{0.7} \mathrm{O}_{2-\delta}$ respectively.

The binding energies for $\mathrm{W}$ and $\mathrm{Er}$ in $\mathrm{W}_{0.2} \mathrm{Er}_{0.1} \mathrm{Ru}_{0.7} \mathrm{O}_{2-\delta}$ after OER were positively shifted compared with those before OER, respectively. This suggested that $\mathrm{W}$ and $\mathrm{Er}$ in $\mathrm{W}_{0.2} \mathrm{Er}_{0.1} \mathrm{Ru}_{0.7} \mathrm{O}_{2-\delta}$ after OER were positively charged (Fig. 8b, c). Compared with $\mathrm{O}$ $1 s$ in $\mathrm{W}_{0.2} \mathrm{Er}_{0.1} \mathrm{Ru}_{0.7} \mathrm{O}_{2-\delta}$ before OER, the lattice $\mathrm{O}$ and $\mathrm{M}-\mathrm{O}$ groups in $\mathrm{W}_{0.2} \mathrm{Er}_{0.1} \mathrm{Ru}_{0.7} \mathrm{O}_{2-\delta}$ after OER were slightly positively shifted, indicating $\mathrm{O} 1 s$ were slightly positively charged after OER (Fig. 8d). Simultaneously, the ratio between the area of the lattice oxygen and $\mathrm{M}-\mathrm{O}$ groups of $\mathrm{W}_{0.2} \mathrm{Er}_{0.1} \mathrm{Ru}_{0.7} \mathrm{O}_{2-\delta}$ after OER stability became smaller, compared with that for $\mathrm{W}_{0.2} \mathrm{Er}_{0.1} \mathrm{Ru}_{0.7}$ $\mathrm{O}_{2-\delta}$ before OER. Additionally, the hydroxyl groups disappeared in $\mathrm{W}_{0.2} \mathrm{Er}_{0.1} \mathrm{Ru}_{0.7} \mathrm{O}_{2-\delta}$ after OER, suggesting the hydroxyl groups were oxidized during OER. The surface rearrangement in $\mathrm{W}_{0.2} \mathrm{Er}_{0.1} \mathrm{Ru}_{0.7} \mathrm{O}_{2-\delta}$ during acidic OER should be responsible for the shift in these electron states (Fig. 8a-d). Simultaneously, after the surface rearrangement, partial electrons from $\mathrm{W}$ and $\mathrm{Er}$ were transferred to $\mathrm{Ru}$ atoms, achieving a charge redistribution among $\mathrm{Ru}, \mathrm{W}, \mathrm{Er}$, and $\mathrm{O}$. The similar redistribution was also observed in $\mathrm{IrO}_{x} / \mathrm{SrIrO}_{3}$ for acidic OER ${ }^{46}$. Remarkably, after electron charge redistribution, $\mathrm{Ru} 4 d$ still keeps $\mathrm{Ru}^{4+}$ without the generation of soluble $\mathrm{Ru}^{x+}(\mathrm{x}>4)$ derivatives. Therefore, charge redistribution among $\mathrm{W}, \mathrm{Er}, \mathrm{Ru}$, and $\mathrm{O}$ is one reason for achieving the long-durable stability of $\mathrm{W}_{0.2} \mathrm{Er}_{0.1} \mathrm{Ru}_{0.7} \mathrm{O}_{2-\delta}$ in acidic OER.

Characterization of $\mathrm{W}_{0.2} \mathrm{Er}_{0.1} \mathrm{Ru}_{0.7} \mathrm{O}_{2-\delta}$ after acidic OER. To prove there was no generation of oxygen vacancies on $\mathrm{W}_{0.2} \mathrm{Er}_{0.1} \mathrm{Ru}_{0.7} \mathrm{O}_{2-\delta}$ during acidic OER, electron spin resonance (ESR) was further applied to characterize $\mathrm{W}_{0.2} \mathrm{Er}_{0.1} \mathrm{Ru}_{0.7} \mathrm{O}_{2-\delta}$ after the stability test (Fig. 8e). ESR spectra revealed that there were no obvious peaks around $3275 \mathrm{G}$ (oxygen vacancies) in $\mathrm{W}_{0.2} \mathrm{Er}_{0.1} \mathrm{Ru}_{0.7} \mathrm{O}_{2-\delta}$, confirming that there were no generation of oxygen vacancies during acidic OER, directly proving co-doping of $\mathrm{W}$ and Er could enhance the energy formation of oxygen vacancies (Supplementary Fig. 2). Simultaneously, it also proved 

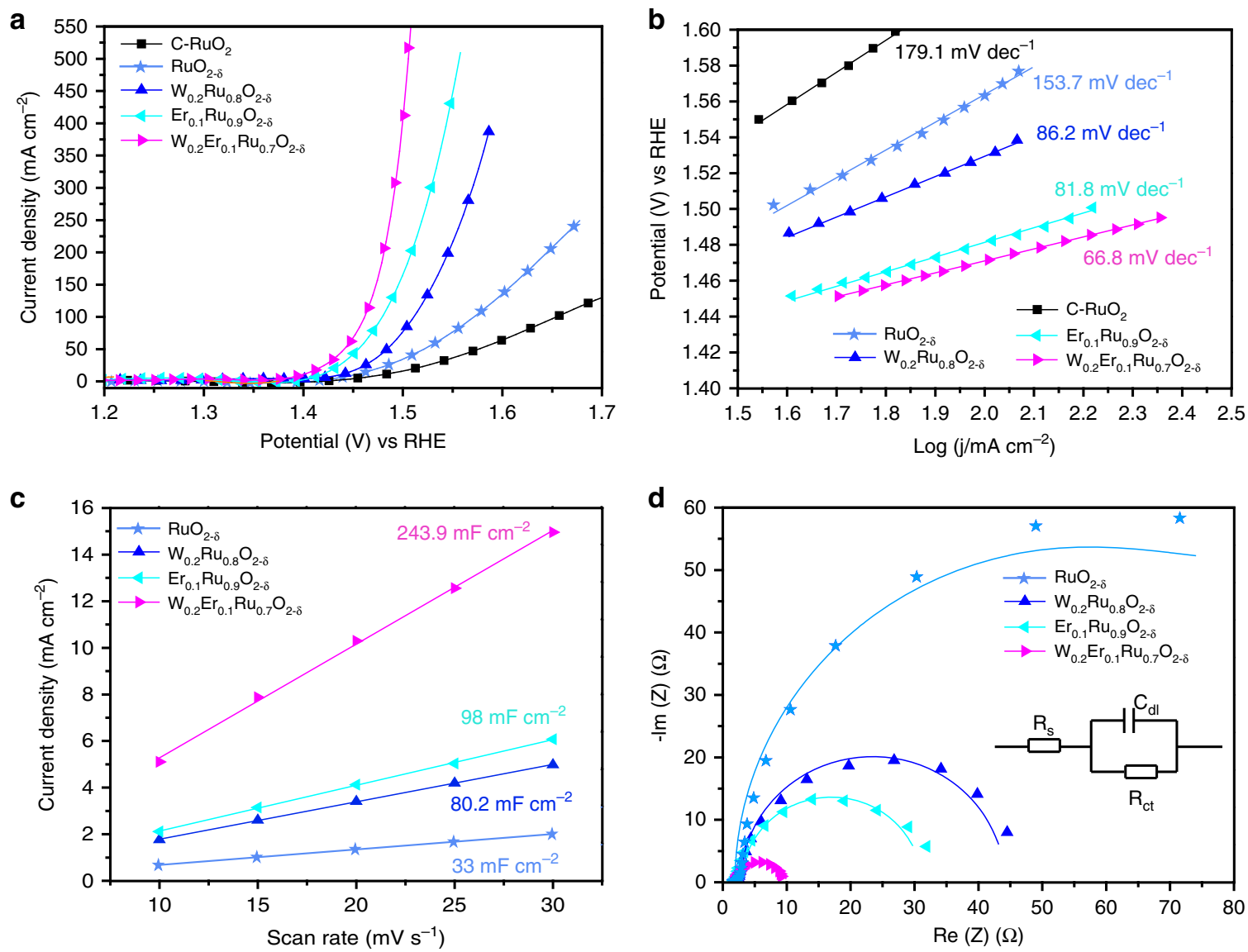

Fig. $\mathbf{6}$ Acidic OER activities for these samples tested in $\mathbf{0 . 5} \mathbf{M ~ H}_{\mathbf{2}} \mathbf{S O}_{\mathbf{4}}$ electrolyte. a Polarization curves, b corresponding Tafel slopes calculated from a. c $C_{\text {dl }}$ plots inferred from CV curves. d ElS plots for $\mathrm{W}_{0.2} \mathrm{Er}_{0.1} \mathrm{Ru}_{0.7} \mathrm{O}_{2-\delta}, \mathrm{Er}_{0.1} \mathrm{Ru}_{0.9} \mathrm{O}_{2-\delta}, \mathrm{W}_{0.2} \mathrm{Ru}_{0.8} \mathrm{O}_{2-\delta}$ and $\mathrm{RuO}_{2-\delta}$ nanosheets.

that the $\mathrm{O}-\mathrm{O}$ coupling was from $\mathrm{H}_{2} \mathrm{O}$, rather than from lattice oxygen (Fig. 1). Consequently, there was no generation of highvalance $\mathrm{RuO}_{4}$, avoiding collapsing the crystal structure of $\mathrm{W}_{0.2} \mathrm{Er}_{0.1} \mathrm{Ru}_{0.7} \mathrm{O}_{2-\delta}$. Additionally, the morphology of the $\mathrm{W}_{0.2} \mathrm{Er}_{0.1} \mathrm{Ru}_{0.7} \mathrm{O}_{2-\delta}$ remained intact after $500 \mathrm{~h}$ operation under acidic electrolyte (Fig. 8f, g). The fractional lattice spacing of $\mathrm{W}_{0.2} \mathrm{Er}_{0.1} \mathrm{Ru}_{0.7} \mathrm{O}_{2-\delta}$ also kept at $\sim 0.356 \mathrm{~nm}$, which may be due to the surface rearrangement during acidic OER (Fig. 8f and Supplementary Fig. 32). The elemental mappings of $\mathrm{W}_{0.2} \mathrm{Er}_{0.1} \mathrm{Ru}_{0.7} \mathrm{O}_{2-\delta}$ revealed that $\mathrm{W}, \mathrm{Er}, \mathrm{Ru}$, and $\mathrm{O}$ were still distributed uniformly in the sample (Fig. 8g), suggesting the unchanged composition. Moreover, XRD pattern of $\mathrm{W}_{0.2} \mathrm{Er}_{0.1} \mathrm{Ru}_{0.7} \mathrm{O}_{2-\delta}$ after OER did not change obviously, implying that the structure kept unchangeable (Supplementary Fig. 33).

In summary, we applied doping engineering with $\mathrm{W}$ and $\mathrm{Er}$ for simultaneously boosting the OER activities and stabilities of $\mathrm{RuO}_{2}$ in acidic electrolyte by tuning electronic structure of $\mathrm{RuO}_{2}$. The generation of oxygen vacancies during OER was thermodynamically difficult due to the obviously downshift $\mathrm{O} 2 p$ band centers, which improved the dissolution and oxidation resistance of $\mathrm{Ru}$. Remarkably, the representative $\mathrm{W}_{0.2} \mathrm{Er}_{0.1} \mathrm{Ru}_{0.7} \mathrm{O}_{2-\delta}$ OER catalyst only required a $168 \mathrm{mV}$ overpotential to reach $10 \mathrm{~mA} \mathrm{~cm}^{-2}$ accompanied with long-durable stability of $500 \mathrm{~h}$ in acidic electrolyte, overwhelmingly outperforming other Ru-based electrocatalysts reported so far. Particularly, the obtained sample could also operate stably for $120 \mathrm{~h}$ at a high current of $100 \mathrm{~mA}$ $\mathrm{cm}^{-2}$ in acidic PEM, further pushing its applications in industrial field. This study not only offers deep insights into tuning electronic properties of catalysts to enhance stabilities, but also opens a new-record horizon for designing electrocatalysts with super activity applying in acidic PEM.

\section{Methods}

Materials: Ruthenium(III) acetate $\left(\mathrm{C}_{14} \mathrm{H}_{21} \mathrm{O}_{14} \mathrm{Ru}_{3}\right)$, Tungsten(VI) chloride $\left(\mathrm{WCl}_{6}\right)$, and Erbium(III) chloride $\left(\mathrm{ErCl}_{3}\right)$ were all directly obtained from Aladdin Reagent (Shanghai) Co., Ltd. $\mathrm{HCl}$ and $\mathrm{H}_{2} \mathrm{SO}_{4}$ was purchased from Sinopharm Co., Ltd. EDTA and citric acid were provided with Shanghai Macklin Biochemical Co., Ltd. Carbon paper (CP) was supplied with Shanghai Hesen Electric Co., Ltd. Ultra-pure (18.2 $\mathrm{M} \Omega \mathrm{cm}^{-1}$ ) water was applied to deal with the prepared electrodes and electrolytes.

Preparation of $\mathrm{RuO}_{2-\delta}, \mathbf{W}_{0.1} \mathrm{Ru}_{0.9} \mathbf{O}_{2-\delta}, \mathbf{W}_{0.2} \mathrm{Ru}_{0.8} \mathbf{O}_{2-\delta}, \mathbf{W}_{0.3} \mathrm{Ru}_{0.7} \mathbf{O}_{\mathbf{2}-\delta}$ $\mathrm{Er}_{0.1} \mathrm{Ru}_{0.9} \mathbf{O}_{\mathbf{2}-\delta}, \mathbf{W}_{0.2} \mathrm{Er}_{0.1} \mathbf{R u}_{0.7} \mathbf{O}_{\mathbf{2}-\delta}$ and $\mathbf{W}_{0.2} \mathrm{Er}_{0.2} \mathrm{Ru}_{0.6} \mathbf{O}_{\mathbf{2}-\delta}$ nanosheets. All samples were prepared by the hydrothermal method. Firstly, $\mathrm{C}_{14} \mathrm{H}_{21} \mathrm{O}_{14} \mathrm{Ru}_{3}(0.07$ mol, $5.02 \mathrm{~g}), \mathrm{WCl}_{6}(0.002 \mathrm{~mol}, 0.79 \mathrm{~g})$, and $\mathrm{ErCl}_{3}(0.001 \mathrm{~mol}, 0.27 \mathrm{~g})$ were added into ultra-pure water with vigorous stirring. Then, EDTA $(0.01 \mathrm{~mol}, 2.92 \mathrm{~g})$ and citric acid $(0.01 \mathrm{~mol}, 1.92 \mathrm{~g})$ was added into ultra-pure water with regulating $\mathrm{pH}$ to 9 by $\mathrm{NH}_{3} \cdot \mathrm{H}_{2} \mathrm{O}$. Finally, the solution containing EDTA and critic acid was added drop-wise into the metal salt solution for reaction for $12 \mathrm{~h}$ at $353 \mathrm{~K}$. The obtained precursors were tiled in a treated porcelain boat and heated to $573 \mathrm{~K}$ for $4 \mathrm{~h}$ and $673 \mathrm{~K}$ for $2 \mathrm{~h}$ with a heating rate of $5 \mathrm{~K} / \mathrm{min}$ in muffle furnace, respectively. The porous $\mathrm{W}_{0.2} \mathrm{Er}_{0.1} \mathrm{Ru}_{0.7} \mathrm{O}_{2-\delta}$ nanosheets were obtained after the muffle furnace cooling to $303 \mathrm{~K}$. The methods for preparation of the $\mathrm{RuO}_{2-\delta}, \mathrm{W}_{0.1} \mathrm{Ru}_{0.9} \mathrm{O}_{2-\delta}$, $\mathrm{W}_{0.2} \mathrm{Ru}_{0.8} \mathrm{O}_{2-\delta}, \mathrm{W}_{0.3} \mathrm{Ru}_{0.7} \mathrm{O}_{2-\delta}, \mathrm{Er}_{0.1} \mathrm{Ru}_{0.9} \mathrm{O}_{2-\delta}$, and $\mathrm{W}_{0.2} \mathrm{Er}_{0.2} \mathrm{Ru}_{0.6} \mathrm{O}_{2-\delta}$ nanosheets were the same as that of $\mathrm{W}_{0.2} \mathrm{Er}_{0.1} \mathrm{Ru}_{0.7} \mathrm{O}_{2-\delta}$ nanosheets.

Characterization. The XRD patterns for prepared electrocatalysts were all obtained on a X-pert Powder (PANalytical B.V., Netherlands) with PIXcel $1 d$ detector and $\mathrm{Cu}-\mathrm{K} \alpha(\lambda=1.54178 \AA)$ radiation. Additionally, Tecnai G2 F20 STWIN (FEI, America) was used to obtain the TEM, HR-STEM, and elemental mapping at a voltage of $200 \mathrm{kV}$. For XPS analysis, X-ray photoelectron spectrometer (Thermo Scientific Escalab Xi+, England) was used to characterize these representative electrocatalysts. For ESR, JEOL FA200 was applied to characterize 

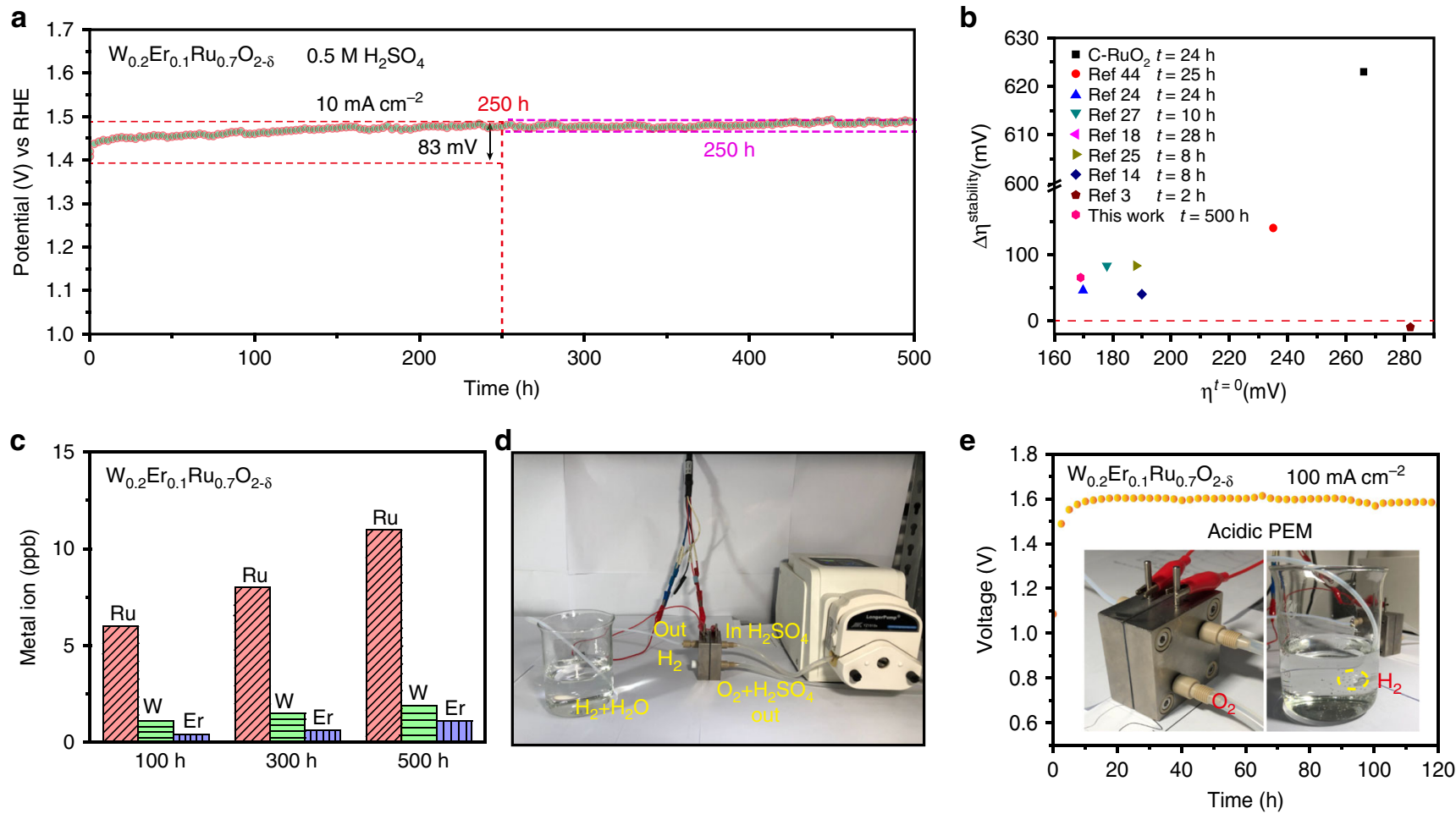

Fig. 7 The long-durable stability investigation for OER and PEM in acidic electrolyte. a The current-time $(500 \mathrm{~h})$ stability of $\mathrm{W}_{0.2} \mathrm{Er}_{0.1} \mathrm{Ru}_{0.7} \mathrm{O}_{2-\delta}$ nanosheets in $0.5 \mathrm{M} \mathrm{H}_{2} \mathrm{SO}_{4}$. b The comparison of stabilities in acidic electrolyte for various electrocatalysts, $x$-axis stands for the initial $\eta$ for electrocatalysts reaching $10 \mathrm{~mA} \mathrm{~cm}^{-2}, y$-axis represents the final $\eta$ of various electrocatalysts after stability measurement. $\mathbf{c} I C P$ analysis for $W_{0.2} E_{0.1} R_{0.7}$ $\mathrm{O}_{2-\delta}$ after $500 \mathrm{~h}$ operation in acidic electrolyte. d Photograph of the employed PEM reaction device. e The current-time $(120 \mathrm{~h}) \mathrm{stability}_{0} \mathrm{~W}_{0.2} \mathrm{Er}_{0.1} \mathrm{Ru}_{0.7}$ $\mathrm{O}_{2-\delta}$ as anodic side in acidic PEM (inset: PEM reaction device, detection of $\mathrm{H}_{2}$ ).

these samples. ICP-MS (Agilent ICP-OES730) was employed to show the ratios of these elements in $\mathrm{W}_{0.2} \mathrm{Er}_{0.1} \mathrm{Ru}_{0.7} \mathrm{O}_{2-\delta}$. BL01C1 Beamline in NSRRC was employed to collect X-ray absorption spectra. Simultaneously, a double-crystal monochromator $(\mathrm{Si}, 111)$ was monochromatized for the radiation. Athena software was employed to analyze the XANES, EXAFS data.

Electrochemical measurements. These prepared electrodes were characterized by Bio-Logic VSP potentiostat. The mass-loading for prepared electrocatalysts on $\mathrm{CP}$ was $0.33 \mathrm{mg} \mathrm{cm}{ }^{-2}$. The prepared $\mathrm{C}-\mathrm{RuO}_{2} / \mathrm{CP}, \mathrm{RuO}_{2-\delta} / \mathrm{CP}, \mathrm{W}_{0.1} \mathrm{Ru}_{0.9} \mathrm{O}_{2-\delta} / \mathrm{CP}$, $\mathrm{W}_{0.2} \mathrm{Ru}_{0.8} \mathrm{O}_{2-\delta} / \mathrm{CP}, \mathrm{W}_{0.3} \mathrm{Ru}_{0.7} \mathrm{O}_{2-\delta} / \mathrm{CP}, \mathrm{Er}_{0.1} \mathrm{Ru}_{0.9} \mathrm{O}_{2-\delta} / \mathrm{CP}$, and $\mathrm{W}_{0.2} \mathrm{Er}_{0.1} \mathrm{Ru}_{0.7} \mathrm{O}_{2}$ ${ }_{-\delta} / \mathrm{CP}, \mathrm{W}_{0.2} \mathrm{Er}_{0.2} \mathrm{Ru}_{0.6} \mathrm{O}_{2-\delta} / \mathrm{CP}\left(1 \times 0.5 \mathrm{~cm}^{2}\right)$ were, respectively, applied as working electrodes. Meanwhile, the platinum column electrode and $\mathrm{Hg} / \mathrm{Hg}_{2} \mathrm{SO}_{4}(0.645 \mathrm{~V})$ were, respectively, employed as counter and reference electrodes. Besides that, LSV with $i \mathrm{R}$ correction was applied to characterize activities of these samples in electrolytic cell $\left(40 \mathrm{~mL}, 0.5 \mathrm{M} \mathrm{H}_{2} \mathrm{SO}_{4}\right)$ with purging $\mathrm{O}_{2}$ about $30 \mathrm{~min}$. The EIS was tested in a range of $0.01-100 \mathrm{kHz}$ at onset potential and open circuit voltage. The stabilities of $\mathrm{C}-\mathrm{RuO}_{2}$ and $\mathrm{W}_{0.2} \mathrm{Er}_{0.1} \mathrm{Ru}_{07} \mathrm{O}_{2-\delta}$ were carried out at $10 \mathrm{~mA} \mathrm{~cm}-2$ toward OER. Additionally, the catalysts loaded on new glass carbon electrodes were employed for the stability test at $10 \mathrm{~mA} \mathrm{~cm}-2$ or $1.4 \mathrm{~V}$ vs. RHE.

The measurement of PEM was performed on the self-made cell, which was composed of two SS316 steel plates. In PEM, the anodic $\mathrm{W}_{0.2} \mathrm{Er}_{0.1} \mathrm{Ru}_{0.7} \mathrm{O}_{2-\delta}$ catalyst and cathodic $\mathrm{Pt} / \mathrm{C}$ (20\%, commercial) were, respectively, sprayed on $\mathrm{Ti}$ foam and $\mathrm{CP}\left(2 \times 2 \mathrm{~cm}^{2}\right)$, respectively. Additionally, the Ti foam and CP-loaded electrocatalysts were fixed with N117 membrane together using hot pressing at 363 $\mathrm{K}$ for $30 \mathrm{~min}$. $0.5 \mathrm{M} \mathrm{H}_{2} \mathrm{SO}_{4}\left(3 \mathrm{~mL} \mathrm{~min}^{-1}\right)$ was applied as electrolyte during the test.

Double layered capacitances $\left(C_{\mathrm{dl}}\right)$ for these samples were assessed by $\mathrm{CV}$ with a san rate from 10 to $30 \mathrm{mV} \mathrm{s}^{-1}$ at a window of $1.01-1.11 \mathrm{~V}$ vs. RHE. The $C_{\mathrm{dl}}$ can be calculated from the scan rates with current densities (j) obtaining from CV curves. Simultaneously, specific capacitance of $40 \mu \mathrm{F} \mathrm{cm}^{-2}$ was applied to assess the ECSA. Additionally, the catalysts loaded on new glass carbon electrodes were also employed for the CV test.

Faradaic efficiency (FE). FE for $\mathrm{W}_{02} \mathrm{Er}_{01} \mathrm{Ru}_{0.7} \mathrm{O}_{2-\delta}$ toward acidic OER $(0.5 \mathrm{M}$ $\mathrm{H}_{2} \mathrm{SO}_{4}$ ) was measured with the three-electrode configuration as well as detected by a GC-9790II gas chromatography. The column is $5 \mathrm{~A}$ molecular sieve (length: $2 \mathrm{~m}$, diameter: $3 \mathrm{~mm}$ ). The detector is thermal conductivity detector (TCD). The electrolyte under stirring was firstly degassed by Ar gas for half an hour. Then, the gaseous sample was taken out with a gas tight syringe every $20 \mathrm{~min}$ at $10 \mathrm{~mA}$.
Additionally, the samples were analyzed via a GC calibrated $\mathrm{O}_{2}$. Each injection into $\mathrm{GC}$ was repeated to eliminate error.

FE could be calculated through Eq.(1):

$$
\mathrm{FE}\left(\mathrm{O}_{2} \%\right)=\frac{V_{\mathrm{O} 2}{ }^{*} 4^{*} F}{V_{\mathrm{m}}{ }^{*}{ }^{*} t^{*} 100 \%},
$$

where $V_{\mathrm{O} 2}$ represents the volume of $\mathrm{O}_{2}, F$ represents Faraday constant $(96,485.33289 \mathrm{C} / \mathrm{mol}), i$ stands for the applying current, $t$ is the total time for OER, and $V_{\mathrm{m}}$ represents the molar volume of the generated $\mathrm{O}_{2}$.

Theoretical calculations. Spin-polarized DFT calculations were conducted on projector-augmented wave (PAW) ${ }^{47}$ in the Vienna Ab initio Simulation Package (VASP) ${ }^{48}$. The generalized gradient approximation (GGA) of Perdew-Burke-Ernzerhof (PBE) ${ }^{49}$ exchange-functional functional was applied. The cut-off energy for plane-wave basis was set as $450 \mathrm{eV}$. A $20 \AA$ vacuum slab in a direction perpendicular to the surface of catalyst was adopted to avoid periodic interactions. The Brillouin zone integration was performed with $3 \times 3 \times 1$

Monkhorst-Pack $k$-point sampling for geometry relaxation ${ }^{50}$. For the calculations of DOS, the $k$-point mesh was increased to $6 \times 6 \times 1$. The convergence threshold for force and energy during optimization were set as $0.03 \mathrm{eV} / \AA \AA^{-}, 10^{-4} \mathrm{eV}$, respectively. A $p(4 \times 4)$ unit cell of $\mathrm{RuO}_{2}$ (110) surface with three layers in their slab was comprised. In the maintext and supplementary information, the influence of neighboring intermediates on the energetics was not considered when free-binding energies were calculated without special instructions. Additonally, the influence of aqueous solvent in calculation were not considered. The first two layers as well as the adsorbate intermediates were relaxed with the fixation of other atoms for geometry optimization. For Er and W doping, three different initial structures are considered, +3 and +6 valences of $\mathrm{Er}$ and $\mathrm{W}$ are taken into account, respectively. It is worth mentioning that the model of Erdoped exhibited a relatively lower energy as compared with Er and W co-doped, because of the larger distortion of the adjacent $\mathrm{O}$ at the Er defect position, another more reasonable structural model is selected. On this basis, we simulated the adsorption behavior of ${ }^{*} \mathrm{O},{ }^{*} \mathrm{OH}$, and ${ }^{*} \mathrm{OOH}$ intermediates for each catalyst, and each model was optimized to convergence. $\Delta G$ for each OER step was calculated through the model of computational hydrogen electrode ${ }^{51}$ along with the equation as following:

$$
\Delta G=\Delta E_{\mathrm{ZPE}}+\Delta E--T \times \Delta S .
$$

The formula for calculation of $\mathrm{V}_{\mathrm{O}}$ :

$$
\Delta G\left(V_{\mathrm{O}}\right)=G\left(V_{\mathrm{O}}\right)+\left(G_{\mathrm{H} 2 \mathrm{O}}-G_{\mathrm{H} 2}\right)-G\left({ }^{*} \mathrm{O}\right)
$$


a
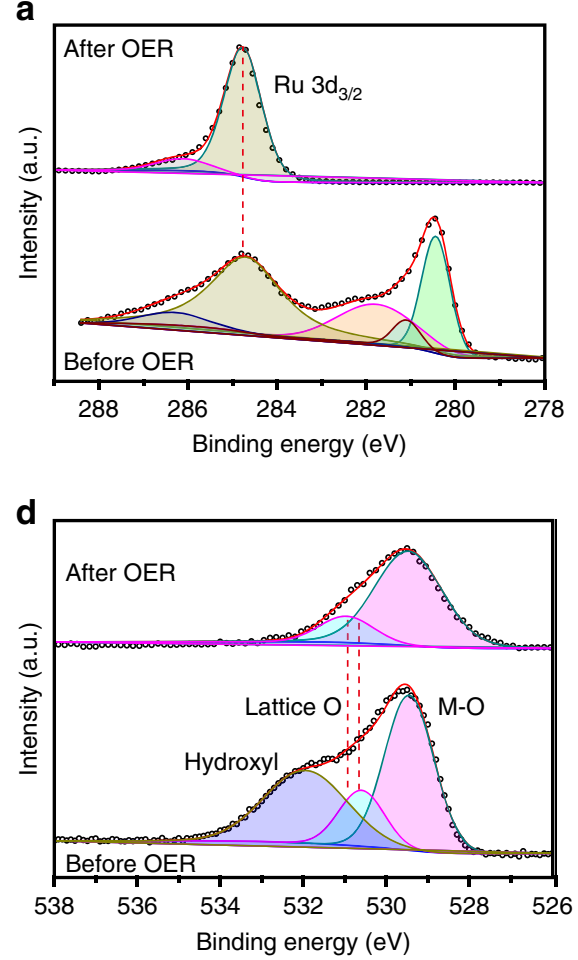
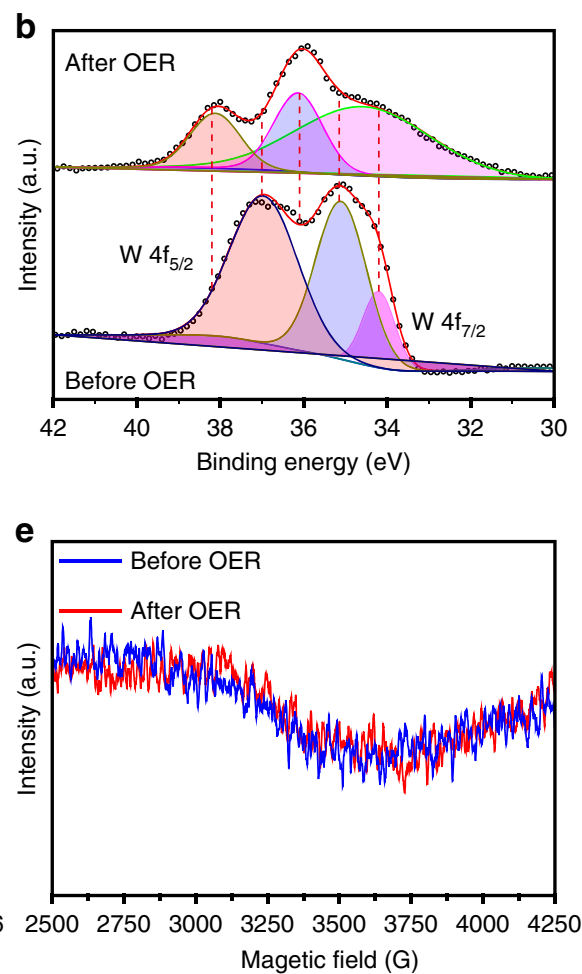
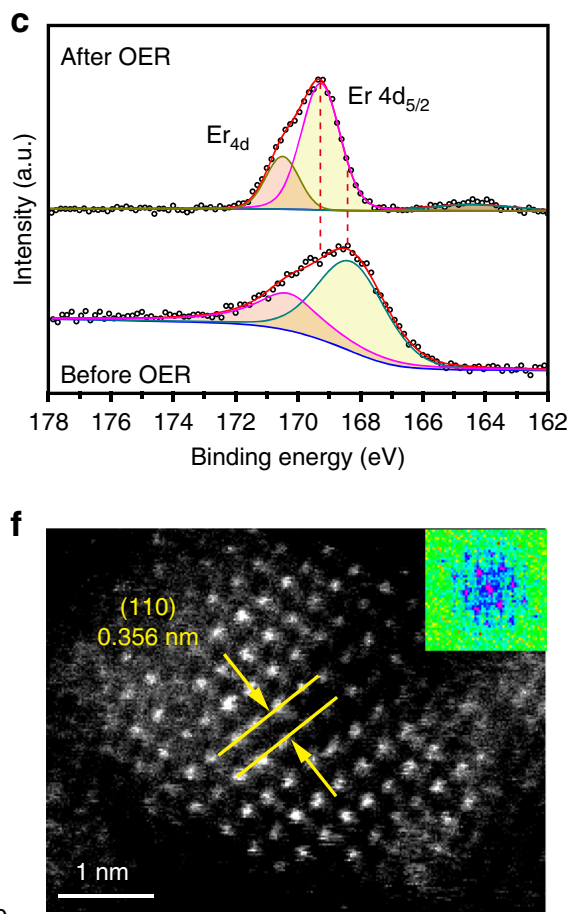
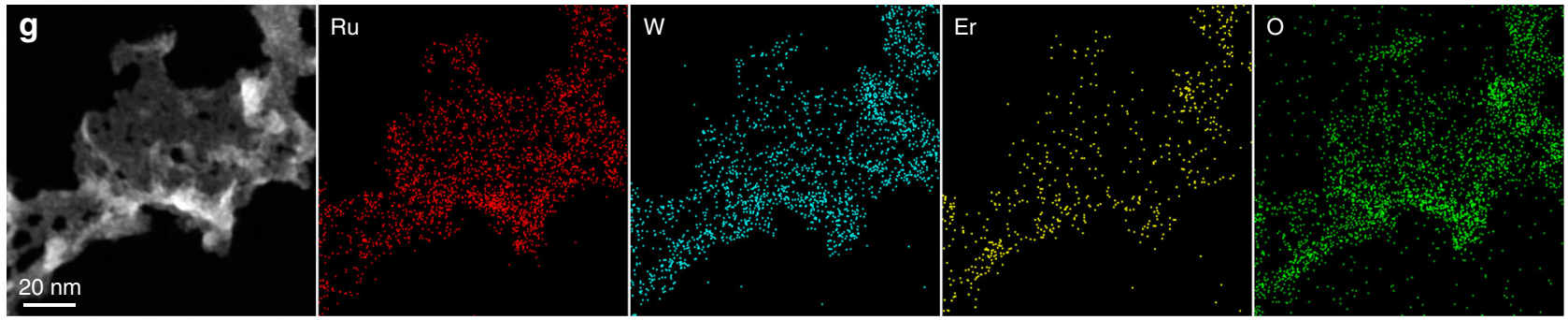

Fig. $\mathbf{8}$ Chemical recognition and characterization for $\mathbf{W}_{\mathbf{0 . 2}} \mathbf{E r}_{\mathbf{0 . 1}} \mathbf{R u}_{\mathbf{0 . 7}} \mathbf{O}_{\mathbf{2}-\delta}$ after $\mathbf{5 0 0} \mathbf{h}$ stability. a Ru $3 d$ spectra, $\mathbf{b} \mathrm{W} 4 f$ spectra, $\mathbf{c}$ Er $4 d$ spectra, $\mathbf{d} \mathrm{O} 1 \mathrm{~s}$ spectra for $\mathrm{W}_{0.2} \mathrm{Er}_{0.1} \mathrm{Ru}_{0.7} \mathrm{O}_{2-\delta}$ before and after $500 \mathrm{~h}$ stability. e ESR spectra for $\mathrm{W}_{0.2} \mathrm{Er}_{0.1} \mathrm{Ru}_{0.7} \mathrm{O}_{2-\delta}$ before and after $500 \mathrm{~h}$ stability. $\mathbf{f} \mathrm{HR}-\mathrm{TEM}$ image, $\mathbf{g}$ Elemental mapping for $\mathrm{W}_{0.2} \mathrm{Er}_{0.1} \mathrm{Ru}_{0.7} \mathrm{O}_{2-\delta}$ after acidic OER stability.

where $\Delta E$ refers to DFT energy difference; $\Delta S$ and $\Delta E_{\mathrm{ZPE}}$ refer to corrections with entropy through vibrational analysis and zero point energy at $300 \mathrm{~K}$, respectively; $G\left(V_{\mathrm{O}}\right)$ refers to the energy of the structure after leaving a vacancy; $G$ $\left({ }^{*} \mathrm{O}\right)$ refers to the energy that adsorbs the structure of ${ }^{*} \mathrm{O}$ intermediate; $G_{\mathrm{H} 2 \mathrm{O}}$ and $G_{\mathrm{H} 2}$ are the energy for water molecules and hydrogen molecules, respectively.

\section{Data availability}

All of the authors claim that the presented data in this work will be available for the contacts from corresponding author with reasonable request.

Received: 23 March 2020; Accepted: 23 September 2020; Published online: 23 October 2020

\section{References}

1. Zhang, B. et al. Homogeneously dispersed multimetal oxygen-evolving catalysts. Science 352, 333 (2016).

2. Sun, H. et al. Self-supported transition-metal-based electrocatalysts for hydrogen and oxygen evolution. Adv. Mater. e1806326 (2019).

3. Shan, J. et al. Charge-redistribution-enhanced nanocrystalline $\mathrm{Ru} @ \mathrm{IrO}_{x}$ electrocatalysts for oxygen evolution in acidic media. Chem 5, 445-459 (2019).
4. Blasco-Ahicart, M., Soriano-López, J., Carbó, J. J., Poblet, J. M. \& GalanMascaros, J. R. Polyoxometalate electrocatalysts based on earth-abundant metals for efficient water oxidation in acidic media. Nat. Chem. 10, 24 (2017)

5. Kasian, O., Grote, J. P., Geiger, S., Cherevko, S. \& Mayrhofer, K. J. J. The common intermediates of oxygen evolution and dissolution reactions during water electrolysis on iridium. Angew. Chem. Int. Ed. 57, 2488-2491 (2018).

6. Geiger, S. et al. The stability number as a metric for electrocatalyst stability benchmarking. Nat. Catal. 1, 508-515 (2018).

7. Nong, H. N. et al. A unique oxygen ligand environment facilitates water oxidation in hole-doped $\mathrm{IrNiO}_{x}$ core-shell electrocatalysts. Nat. Catal. 1, 841-851 (2018).

8. King, L. A. et al. A non-precious metal hydrogen catalyst in a commercial polymer electrolyte membrane electrolyser. Nat. Nanotechnol. 14, 1071-1074 (2019).

9. Tobias Reier, H. N. N., Teschner, D., Schlögl, R. \& Strasser, P. Electrocatalytic oxygen evolution reaction in acidic environments-reaction mechanisms and catalysts. Adv. Energy Mater. 7, 1601275 (2017).

10. Kibsgaard, J. \& Chorkendorff, I. Considerations for the scaling-up of water splitting catalysts. Nat. Energy 4, 430-433 (2019).

11. Chatti, M. et al. Intrinsically stable in situ generated electrocatalyst for longterm oxidation of acidic water at up to $80^{\circ} \mathrm{C}$. Nat. Catal. 2, 457-465 (2019).

12. Lei Wang, Z. Z. et al. Tunable intrinsic strain in two-dimensional transition metal electrocatalysts. Science 363, 870-874 (2019).

13. Cao, L. et al. Dynamic oxygen adsorption on single-atomic ruthenium catalyst with high performance for acidic oxygen evolution reaction. Nat. Commun. 10, 4849 (2019) 
14. Kim, J. et al. High-performance pyrochlore-type yttrium ruthenate electrocatalyst for oxygen evolution reaction in acidic media. J. Am. Chem. Soc. 139, 12076-12083 (2017).

15. Gao, J. et al. Breaking long-range order in iridium oxide by alkali ion for efficient water oxidation. J. Am. Chem. Soc. 141, 3014-3023 (2019).

16. Shang, C. et al. Electron correlations engineer catalytic activity of pyrochlore iridates for acidic water oxidation. Adv. Mater. 31, e1805104 (2019).

17. Zhao, M. et al. Ru octahedral nanocrystals with a face-centered cubic structure, $\{111\}$ facets, thermal stability up to 400 degrees $C$, and enhanced catalytic activity. J. Am. Chem. Soc. 141, 7028-7036 (2019).

18. Yao, Y. et al. Engineering the electronic structure of single atom Ru sites via compressive strain boosts acidic water oxidation electrocatalysis. Nat. Catal. 2, 304-313 (2019).

19. Shan, J., Zheng, Y., Shi, B., Davey, K. \& Qiao, S. Z. Regulating electrocatalysts via surface and interface engineering for acidic water electrooxidation. ACS Energy Lett. 4, 2719-2730 (2019).

20. Stoerzinger, K. A. et al. Orientation-dependent oxygen evolution on $\mathrm{RuO}_{2}$ without lattice exchange. ACS Energy Lett. 2, 876-881 (2017)

21. Rossmeisl, J., Qu, Z. W., Zhu, H., Kroes, G. J. \& Nørskov, J. K. Electrolysis of water on oxide surfaces. J. Electroanal. Chem. 607, 83-89 (2007).

22. Exner, K. S. Design criteria for oxygen evolution electrocatalysts from First Principles: introduction of a unifying material-screening approach. ACS Appl. Energy Mater. 2, 7991-8001 (2019).

23. Retuerto, M. et al. Na-doped ruthenium perovskite electrocatalysts with improved oxygen evolution activity and durability in acidic media. Nat. Commun. 10, 2041 (2019).

24. Miao, X. et al. Quadruple perovskite ruthenate as a highly efficient catalyst for acidic water oxidation. Nat. Commun. 10, 3809 (2019).

25. Su, J. et al. Assembling ultrasmall copper-doped ruthenium oxide nanocrystals into hollow porous polyhedra: highly robust electrocatalysts for oxygen evolution in acidic media. Adv. Mater. el801351 (2018).

26. Ge, R. et al. Ultrafine defective $\mathrm{RuO}_{2}$ electrocatayst integrated on carbon cloth for robust water oxidation in acidic media. Adv. Energy Mater. 9, 1901313 (2019).

27. Lin, Y. et al. Chromium-ruthenium oxide solid solution electrocatalyst for highly efficient oxygen evolution reaction in acidic media. Nat. Commun. 10, 162 (2019).

28. Grimaud, A. et al. Activating lattice oxygen redox reactions in metal oxides to catalyse oxygen evolution. Nat. Chem. 9, 457-465 (2017).

29. Teliska, M., O'Grady, W. E. \& Ramaker, D. E. Determination of O and OH adsorption sites and coverage in situ on Pt electrodes from Pt L23 X-ray absorption spectroscopy. J. Phys. Chem. B 109, 8076-8084 (2005).

30. Fang, Y. H. \& Liu, Z. P. Mechanism and Tafel lines of electro-oxidation of water to oxygen on $\mathrm{RuO}_{2}$ (110). J. Am. Chem. Soc. 132, 18214-18222 (2010).

31. Wohlfahrt-Mehrens, M. \& Heitbaum, J. Oxygen evolution on Ru and $\mathrm{RuO}_{2}$ electrodes studied using isotope labelling and on-line mass spectrometry. $J$. Electroanal. Chem. Interfacial Electrochem. 237, 251-260 (1987).

32. Macounova, K., Makarova, M. \& Krtil, P. Oxygen evolution on nanocrystalline $\mathrm{RuO}_{2}$ and $\mathrm{Ru}_{0.9} \mathrm{Ni}_{0.1} \mathrm{O}_{2-\delta}$ electrodes-DEMS approach to reaction mechanism determination. Electrochem. Commun. 11, 1865-1868 (2009).

33. Mefford, J. T. et al. Water electrolysis on $\mathrm{La}_{(1-\mathrm{x})} \mathrm{Sr}_{(\mathrm{x})} \mathrm{CoO}_{(3-\text { delta) }}$ perovskite electrocatalysts. Nat. Commun. 7, 11053 (2016).

34. Grimaud, A., Hong, W. T., Shao-Horn, Y. \& Tarascon, J. M. Anionic redox processes for electrochemical devices. Nat. Mater. 15, 121-126 (2016).

35. Zagalskaya, A. \& Alexandrov, V. Role of defects in the interplay between adsorbate evolving and lattice oxygen mechanisms of the oxygen evolution reaction in $\mathrm{RuO}_{2}$ and $\mathrm{IrO}_{2}$. ACS Catal. 10, 3650-3657 (2020).

36. Halck, N. B., Petrykin, V., Krtil, P. \& Rossmeisl, J. Beyond the volcano limitations in electrocatalysis-oxygen evolution reaction. Phys. Chem. Chem. Phys. 16, 13682-13688 (2014).

37. Huang, Z. F. et al. Chemical and structural origin of lattice oxygen oxidation in $\mathrm{Co}-\mathrm{Zn}$ oxyhydroxide oxygen evolution electrocatalysts. Nat. Energy 4, 329-338 (2019).

38. Man, I. C. et al. Universality in oxygen evolution electrocatalysis on oxide surfaces. ChemCatChem 3, 1159-1165 (2011)

39. Exner, K. S. Universality in oxygen evolution electrocatalysis: high-throughput screening and a priori determination of the rate-determining reaction step. ChemCatChem 12, 2000-2003 (2020).

40. Shen, J. Y., Adnot, A. \& Kaliaguine, S. An ESCA study of the interaction of oxygen with the surface of ruthenium. Appl. Surf. Sci. 51, 47-60 (1991).

41. Petrykin, V. et al. Local structure of nanocrystalline $\mathrm{Ru}_{1-\mathrm{x}} \mathrm{Ni}_{\mathrm{x}} \mathrm{O}_{2-\delta}$ dioxide and its implications for electrocatalytic behavior-an XPS and XAS study. J. Phys. Chem. C 113, 21657-21666 (2009).
42. Kumari, S. et al. A low-noble-metal $\mathrm{W}_{1-\mathrm{x}} \mathrm{Ir}_{\mathrm{x}} \mathrm{O}_{3-\delta}$ water oxidation electrocatalyst for acidic media via rapid plasma synthesis. Energy Environ. Sci. 10, 2432-2440 (2017).

43. Reszczyńska, J. et al. Visible light activity of rare earth metal doped $\left(\operatorname{Er}^{3+}\right.$ $\mathrm{Yb}^{3+}$ or $\left.\mathrm{Er}^{3+} / \mathrm{Yb}^{3+}\right)$ titania photocatalysts. Appl. Catal. B-Environ. 163, 40-49 (2015).

44. Shan, J., Ling, T., Davey, K., Zheng, Y. \& Qiao, S. Z. Transition-metal-doped RuIr bifunctional nanocrystals for overall water splitting in acidic environments. Adv. Mater. 31, e1900510 (2019)

45. Jiang, J. et al. Atomic-level insight into super-efficient electrocatalytic oxygen evolution on iron and vanadium co-doped nickel (oxy)hydroxide. Nat. Commun. 9, 2885 (2018).

46. Seitz, L. C. et al. A highly active and stable $\mathrm{IrO}_{\mathrm{x}} / \mathrm{SrIrO}_{3}$ catalyst for the oxygen evolution reaction. Science 353, 1011-1014 (2016).

47. Blöchl, P. E. Projector augmented-wave method. Phys. Rev. B 50, 17953-17979 (1994).

48. Kresse, G. \& Furthmüller, J. Efficient iterative schemes for ab initio total-energy calculations using a plane-wave basis set. Phys. Rev. B 54, 11169-11186 (1996)

49. Perdew, J. P., Burke, K. \& Ernzerhof, M. Generalized gradient approximation made simple. Phys. Rev. Lett. 77, 3865-3868 (1996).

50. Weiler, M., Aggarwal, R. \& Lax, B. Interband magnetoreflectance in semiconducting $\mathrm{Hg}_{1-\mathrm{x}} \mathrm{Cd}_{\mathrm{x}}$ Te alloys. Phys. Rev. B 16, 3603-3607 (1977).

51. Nørskov, J. et al. Origin of the overpotential for oxygen reduction at a fuel-cell cathode. J. Phys. Chem. B 108, 17886-17892 (2004).

\section{Acknowledgements}

Zhejiang Provincial Natural Science Foundation of China (Grant No. LR17B060003) Natural Science Foundation of China (Project Nos. 21872174, U1932148, 21776248, and 21676246), and International Science and Technology Cooperation Program (Grant Nos. 2017YFE0127800 and 2018YFE0203400) supported this work. This study was also supported by the Fundamental Research Funds for the Central Universities (2020XZZX002-07).

\section{Author contributions}

S.Y.H. synthesized the catalysts. S.Y.H. analyzed the data and wrote the manuscript. M.L. and X.W.Z. revised the manuscript. J.J.P., X.N.L., X.L.T., Y.H. and N.X. conducted the theoretical calculations. L.C.L. helped revise the manuscript. All the authors commented the results and approved the final version of the manuscript.

\section{Competing interests}

The authors declare no competing interests.

\section{Additional information}

Supplementary information is available for this paper at https://doi.org/10.1038/s41467 020-19212-y.

Correspondence and requests for materials should be addressed to X.Z.

Peer review information Nature Communications thanks Qianwang Chen, Kai Exner, and Maria Retuerto for their contributions to the peer review of this work.

Reprints and permission information is available at http://www.nature.com/reprints

Publisher's note Springer Nature remains neutral with regard to jurisdictional claims in published maps and institutional affiliations.

Open Access This article is licensed under a Creative Commons Attribution 4.0 International License, which permits use, sharing, adaptation, distribution and reproduction in any medium or format, as long as you give appropriate credit to the original author(s) and the source, provide a link to the Creative Commons license, and indicate if changes were made. The images or other third party material in this article are included in the article's Creative Commons license, unless indicated otherwise in a credit line to the material. If material is not included in the article's Creative Commons license and your intended use is not permitted by statutory regulation or exceeds the permitted use, you will need to obtain permission directly from the copyright holder. To view a copy of this license, visit http://creativecommons.org/ licenses/by/4.0/

(C) The Author(s) 2020 